Published in final edited form as:

Cochrane Database Syst Rev. ; 11: CD008552. doi:10.1002/14651858.CD008552.pub2.

\title{
Interventions for increasing fruit and vegetable consumption in children aged 5 years and under
}

\author{
Luke Wolfenden ${ }^{1}$, Rebecca J Wyse ${ }^{1}$, Ben I Britton ${ }^{2}$, Karen J Campbell ${ }^{3}$, Rebecca K \\ Hodder $^{4}$, Fiona G Stacey ${ }^{5}$, Patrick McElduff ${ }^{6}$, and Erica L James ${ }^{5}$ \\ ${ }^{1}$ School of Medicine and Public Health, University of Newcastle, Callaghan, Australia \\ ${ }^{2}$ Newcastle Calvary Mater Hospital, NSW, Australia \\ ${ }^{3}$ Centre for Physical Activity and Nutrition Research, School of Exercise and Nutrition Sciences, \\ Deakin University, Burwood, VIC, Australia \\ ${ }^{4}$ Hunter New England Population Health, Wallsend, NSW, Australia \\ ${ }^{5}$ School of Medicine and Public Health, University of Newcastle, Hunter Medical Research \\ Institute, Priority Research Centre in Health Behaviour, and Priority Research Centre in Physical \\ Activity and Nutrition, Callaghan, Australia \\ ${ }^{6}$ School of Medicine and Public Health, Hunter Medical Research Institute, University of \\ Newcastle, Callaghan, NSW, Australia
}

\section{Abstract \\ Background-Insufficient consumption of fruits and vegetables in childhood increases the risk of future chronic diseases including cardiovascular disease.}

Objectives-To assess the effectiveness, cost-effectiveness and associated adverse events of interventions designed to increase the consumption of fruit and/or vegetables amongst children aged five years and under.

\begin{abstract}
Search methods-The Cochrane Central Register of Controlled Trials (CENTRAL) in The Cochrane Library Issue 2, 2010, MEDLINE (1950 to 2010 April week 4), EMBASE (1947 to 2010 week 18), CINAHL (up to 12 May 2010), PsycINFO (up to 12 May 2010) and Proquest Dissertations and Theses (up to February 2011) were searched to identify eligible trials, as well as
\end{abstract}

Copyright @ 2012 The Cochrane Collaboration. Published by John Wiley \& Sons, Ltd

Contact address: Luke Wolfenden, School of Medicine and Public Health, University of Newcastle, Callaghan, NSW, 2308, Australia. luke.wolfenden@hnehealth.nsw.gov.au.

Editorial group: Cochrane Heart Group.

Publication status and date: New, published in Issue 11, 2012.

Review content assessed as up-to-date: 28 February 2011.

CONTRIBUTIONS OF AUTHORS

Luke Wolfenden led the development of the review. All authors contributed to the conception of the research and were involved in the preparation of the review including providing critical comment on drafts. Luke Wolfenden, Fiona Stacey and Rebecca Hodder screened titles and abstracts and determined study eligibility. Rebecca Wyse, Ben Britton and Erica James extracted data from eligible trials, and assessed heterogeneity and risk of bias. Patrick McElduff provided statistical advice.

DECLARATIONS OF INTEREST

Luke Wolfenden, Rebecca Wyse and Karen Campbell are currently undertaking a randomised trial of an intervention to increase fruit and vegetable consumption. The authors have not received any benefit, in cash or kind, any hospitality, or any subsidy derived from the food industry or any other source perceived to have an interest in the outcome of the review. 
electronic trial registers (also up to February 2011). The reference lists of included trials were reviewed and handsearches of three international nutrition journals were also performed. Authors of all included trials were contacted in order to identify further potentially relevant trials.

Selection criteria-We included randomised controlled trials (RCTs), including clusterrandomised controlled trials, of any intervention primarily targeting fruit and/or vegetable consumption among children aged five years and under and incorporating a biochemical or dietary assessment of fruit and/or vegetable consumption. Two review authors independently screened the titles and abstracts of identified papers. A third review author with expertise in review methodology resolved any disagreements regarding study eligibility.

Data collection and analysis-Two review authors independently extracted data and assessed the risk of bias of the included studies. A third reviewer resolved disagreements between review authors. Fixed-effect models were used to perform meta-analysis for the primary review outcomes where a sufficient number of trials with suitable data and homogeneity were identified.

Main results-Five trials, with 13 trial arms and 3967 participants were included in the review. Two trials examined the impact of specific feeding practices (e.g. repeated food exposure) in increasing child intake of a target vegetable. Two trials assessed the effectiveness of home visiting programs implemented in disadvantaged communities and one trial investigated the effect of a preschool-based intervention in increasing child fruit and vegetable intake. Risk of bias of included studies was low although three of the five trials were judged to be at high risk of performance bias. Meta-analysis of two trials examining repeated food exposure versus a no intervention comparison found no significant difference in target vegetable consumption in the short term (mean difference (MD) 1.37, 95\% confidence interval (CI) -2.78 to 5.52). Coupling repeated food exposure with a tangible non-food or social reward, was effective in increasing targeted vegetable consumption in the short term based on one trial. Home visiting programs provided to disadvantaged groups did not significantly increase overall fruit intake in the short term (standardised mean difference (SMD) $0.01,95 \%$ CI -0.09 to 0.11 ). Similarly, a multicomponent preschool-based intervention failed to significantly increase child consumption of vegetables, but did report a small significant increase in mean child consumption of fruit, six months following baseline assessment. None of the trials investigated intervention costeffectiveness or reported information regarding any adverse events or unintended adverse consequences of the intervention.

Authors' conclusions-Despite the importance of encouraging fruit and vegetable consumption among children aged five years and under, this review identified few randomised controlled trials investigating interventions to achieve this.

\section{Medical Subject Headings (MeSH)}

*Eating; *Feeding Behavior; *Fruit; *Vegetables; Conditioning (Psychology); House Calls; Randomized Controlled Trials as Topic; Reward

\section{MeSH check words}

Child, Preschool; Humans; Infant 


\section{BACKGROUND}

\section{Description of the condition}

Chronic diseases are illnesses which are typically prolonged in duration, do not resolve spontaneously and are rarely cured completely (Australian Institute of Health and Welfare 2002). Insufficient consumption of fruits and vegetables is associated with a range of chronic diseases such as cancer and cardiovascular disease (World Health Organization 2003; World Health Organization 2011). Globally, $2.9 \%$ of all deaths and $1.1 \%$ of all disability-adjusted life years (DALYs) each year are attributable to inadequate fruit and vegetable intake (World Health Organization 2009). Low fruit and vegetable consumption is responsible for $11 \%$ of all ischaemic heart disease and $9 \%$ of all stroke deaths (World Health Organization 2009). Increasing global fruit and vegetable intake, therefore, represents a public health priority and has the capacity to reduce the burden of coronary heart disease by $31 \%$ (Lock 2005).

Consumption of at least 400 grams per day of fruit and vegetables is recommended to reduce the risk of chronic diseases (World Health Organization 1997). Nationally representative surveys, however, indicate that throughout most regions of the globe, daily consumption of fruits and vegetables is well below such recommendations (Lock 2005).

Population surveys of children indicate the need to increase the intake of fruits and vegetables (Lock 2005; World Health Organization 2004a; Yngve 2005). For example, less than a third of school-aged children from European nations report consuming vegetables on a daily basis (World Health Organization 2004a). While the mean intake of fruit and vegetables is below the WHO recommendations across all WHO regions, South American, African, and South East Asian nations report the lowest quantities of child fruit and vegetable intake, where school-aged children typically consume less than 300 grams per day (Lock 2005). Longitudinal studies suggest that eating behaviours established in childhood are likely to persist into adulthood (Lien 2001; Mikkilä 2004). Encouraging healthy eating among children may, therefore, represent a particularly effective primary prevention strategy for reducing the risk of chronic diseases (Maynard 2003; Ness 2005). Thirty seven year follow-up data from the Boyd Orr cohort study of British children, for example, found lower rates of all cause cardiovascular mortality among children with greater intake of vegetables in childhood (Ness 2005). In addition, adequate fruit and vegetable intake during childhood may have a number of immediate beneficial impacts, including reducing the risk of micronutrient deficiencies and a number of respiratory illnesses (Antova 2003; Forastiere 2005; World Health Organization 2003).

\section{Description of the intervention}

The aetiology of fruit and vegetable consumption is complex, involving the dynamic interaction of a variety of factors. Given such complexity, a number of frameworks have been utilised to guide the development of interventions to increase fruit and vegetable intake (Klepp 2005; Miller 2000; World Health Organization 2004b). The conceptual framework developed for the international Pro Children Project suggests that interventions targeting a variety of cultural, physical and social environment factors, as well as those targeting 
personal factors may be effective in positively influencing fruit and vegetable intake among children (Klepp 2005). Despite the range of potential intervention targets, previous trials have tended to focus on those determinants more amenable to intervention, such as nutrition knowledge and skills, or the food environment of settings such as schools (Hector 2008). Among school-aged children, systematic reviews suggest that the strongest evidence exists for the efficacy of interventions specifically targeting fruit and vegetable consumption rather than broader healthy eating interventions, multi-component school-based interventions, and interventions incorporating a parent or family element (Blanchette 2005; Burchett 2003; Ciliska 2000; French 2003; Knai 2006). Similar strategies would be hypothesised to be effective for children aged five years and under.

\section{How the intervention might work}

A number of theories have been used to explain a mechanism by which interventions may be able to influence fruit and vegetable consumption of children (Rasmussen 2006). In most instances, psychosocial theories such as Social Cognitive Theory (Bandura 1986), the Theory of Planned Behaviour (Ajzen 1991), or the Stages of Change Trans-theoretical Model (Prochaska 1984) have been used to explain possible causal pathways to fruit and vegetable consumption (Rasmussen 2006). Collectively, such theories assert that changes to attitudes, knowledge and skills and perceived norms and expectancies are required for behavioural change. The international Pro Children Project incorporated Social-Ecological Theory in its conceptual theoretical framework of determinants of children's fruit and vegetable consumption (Klepp 2005). Interventions derived from Social-Ecological Theory recognise the importance of more structural influences on the fruit and vegetable consumption of children, for example, the availability or accessibility of fruit and vegetables in the home or in settings such as schools which children frequent.

\section{Why it is important to do this review}

Previous reviews have identified a number of factors associated with fruit and vegetable consumption among children (Blanchette 2005; Pearson 2008; Rasmussen 2006; van der Horst 2007). While such reviews provide important information for the development of interventions, only systematic reviews of intervention trials are able to determine the efficacy of strategies to increase child fruit and vegetable consumption. A number of such reviews have been published (Burchett 2003; Ciliska 2000; Delgado-Noguera 2011; French 2003; Howerton 2007; Knai 2006). However, few have included children aged five years and under, and most lacked important information relevant to practice, such as the effectiveness of interventions for various subpopulations (such as minority groups), the costeffectiveness of interventions, or the presence of any unintended adverse effects of the intervention. Similarly, as positive impacts of health behaviour interventions may not be sustained, an examination of the longer-term (> 12 months post-intervention) effectiveness of interventions is important for policy makers and practitioners to assess the potential health benefit of fruit and vegetable intervention (Fjeldsoe 2011; Jones 2011). Previous reviews have not specifically examined the impact of interventions based on the length of post-intervention follow-up. Therefore, a comprehensive systematic review on this issue is required to provide guidance for practitioners and policy makers interested in implementing strategies to promote the consumption of fruits and vegetables in early childhood. 


\section{OBJECTIVES}

To assess the effectiveness, cost-effectiveness and associated adverse events of interventions designed to increase the consumption of fruit and/or vegetables among children aged five years and under.

\section{METHODS}

\section{Criteria for considering studies for this review}

Types of studies-Eligible trials were randomised controlled trials (RCTs), including cluster-randomised controlled trials, that were published in a peer reviewed journal and that:

1. compared two or more alternative intervention programs to increase the consumption of fruit and/or vegetables of children aged five years and under; or

2. compared an intervention program to increase the consumption of fruit and/or vegetables of children aged five years and under with a standard care or no intervention control group.

Randomised trials which did not include fruit or vegetable intake as the primary trial outcome were excluded.

Types of participants-Participants could include:

1. children aged five years and under. Trials including children older than five years were included only if the mean age of the study sample at baseline was five years or less;

2. parents, guardians and families responsible for the care of children aged five years and under;

3. professionals responsible for the care of children aged five years and under including childcare staff and health professionals.

Types of interventions-Any educational, experiential, health promotion and/or psychological or family or behavioural therapy or counselling or management or structural or policy or legislative reform interventions designed to increase fruit and/or vegetable consumption in children aged five years and under (as defined in types of participants) were considered for inclusion. Interventions could be conducted in any setting including the home, childcare/preschool services, health services, or community settings.

Comparison: Any alternate intervention to encourage fruit and vegetable consumption as described above, or a no intervention control or attention control or wait-list control.

Types of outcome measures-Studies with evaluated outcomes measuring biomedical and/or dietary indices were included.

Primary outcomes: The primary outcome was fruit and vegetable intake. Fruit and vegetable intake could be assessed using a variety of measures including: 
a. Change in the number of portions or serves of daily fruit and/or vegetable intakes at follow-up as measured by diet recalls, food diaries, food frequency questionnaires or diet records completed by an adult on behalf of the child. Short-term effects $(<$ 12 months post-intervention) and long-term effects (at least 12 months postintervention) were included.

b. Change in grams of fruit and/or vegetable intakes at follow-up as measured by diet recalls, food diaries, food frequency questionnaires or diet records completed by an adult on behalf of the child. Short-term effects ( $<12$ months post-intervention) and long-term effects (at least 12 months post-intervention) were included.

c. Changes in biomedical markers of fruit and/or vegetable consumption, such as carotene, -carotene, cryptoxanthin, lycopene and lutein. Short-term effects $(<12$ months post-intervention) and long-term effects (at least 12 months postintervention) were included.

\section{Secondary outcomes}

a. Estimates of absolute costs and cost-effectiveness of interventions to increase the consumption of fruits and/or vegetables reported in identified studies were included.

b. Any reported adverse events of an intervention to increase the consumption of fruits and vegetables reported in identified studies were included. This could include any physical, behavioural, psychological or financial impact on the child, parent or family, or the service or facility where an intervention may have been implemented.

\section{Search methods for identification of studies}

We obtained relevant trials published in any language via searches of electronic bibliographic databases, dissertations, handsearching of relevant journals, and following direct communication with authors of included studies.

Electronic searches-We searched electronic databases including the Cochrane Central Register of Controlled Trials (CENTRAL) in The Cochrane Library Issue 2, 2010, MEDLINE (1950 to 2010 April week 4), EM-BASE (1947 to 2010 week 18), CINAHL (up to 12 May 2010) and PsycINFO (up to 12 May 2010). The search strategies are described in Appendix 1.

Searching other resources-We searched the reference lists of relevant articles and performed a handsearch of all articles published between 2006 and October 2010 in three relevant international peer reviewed journals (Journal of Nutrition Education and Behavior, Public Health Nutrition, and Journal of the American Dietetic Association).

We searched the metaRegister of clinical trials, www.controlled-trials.com/mrct/, (up to February 2011) and the WHO International Clinical Trials Registry Platform, www.who.int/ ictrp/, (up to February 2011). Databases of published dissertations (Proquest Dissertations and Theses) were searched (up to February 2011) to identify and contact key authors in an 
attempt to obtain trials published in peer reviewed journals as well as ongoing trials. Ongoing studies are described, where available, detailing the primary author, research question(s), methods and outcome measures.

\section{Data collection and analysis}

Selection of studies-Two review authors (FS and RH) independently screened titles and abstracts of identified papers. Review authors were not blind to the details of the study author or journal. Review authors applied a standardised screening tool to assess eligibility. Papers were screened against the eligibility criteria for the review in a sequential manner, and a paper was excluded based on the first reason for exclusion (order: Participants, Outcome, Comparator, Intervention, RCT). Based on the paper's title and abstract, papers which clearly did not meet the eligibility criteria of the review were excluded. Two review authors (RH and FS) then independently examined the full text of all remaining papers. Information regarding the reason for ineligibility of any paper for which the full text was reviewed was documented and is presented in the table 'Characteristics of excluded studies'. A third review author with expertise in review methodology (LW) resolved any disagreement between review authors (FS and $\mathrm{RH}$ ) regarding study eligibility. For those papers which did not provide sufficient information to determine eligibility, we contacted the study authors for clarification.

Data extraction and management-Two review authors (RW and BB or EJ) independently extracted data from each included trial. Review authors were not blind to the details of the study author or journal. Data were recorded on data extraction forms designed and piloted specifically for this review. Consultation with a third review author with expertise in review methodology $(\mathrm{LW})$ resolved discrepancies between review authors (RW and BB or EJ) regarding data extraction. Attempts were made to contact authors of included papers in instances where the information required for data extraction was not available from the published report, or was unclear. One review author transcribed extracted data into the systematic review software 'Review Manager'. Where available, the following information was extracted from included trials:

1. Information on the study, research design and methods such as: the study authors; date of publication; date of study initiation; study duration; setting; number of participants; participants' age, gender, ethnicity, and socioeconomic position; sequence generation; allocation concealment; blinding of participants, personnel and outcome assessors; and other concerns regarding bias.

2. Information on the experimental conditions of the trial such as the number of experimental conditions; and intervention and comparator components, duration, number of contacts, modalities, interventionist and integrity.

3. Information on the trial outcomes and results such as rates of recruitment and attrition; sample size; number of participants per experimental condition; mean and standard deviation of the primary or secondary outcomes described above; any subgroup analyses by gender, population group or intervention characteristics; and incomplete outcome data. 
Assessment of risk of bias in included studies-Two review authors independently assessed the risk of bias in the included studies (RW and BB or EJ). A third review author with expertise in review methodology was consulted to resolve any disagreements between review authors (LW). Authors used the tool outlined in the Cochrane Handbook for Systematic Reviews of Interventions (Higgins 2011) to assess the risk of bias. The tool requires an explicit judgement by the review authors, based on trial information, regarding the risk of bias attributable to the generation of the random sequence, the allocation concealment, the blinding of participants, personnel and outcome assessors, the completeness of outcome data, selective reporting and any other potential threats to validity. Judgements regarding the risk of bias for each trial were recorded in the 'Risk of Bias' table accompanying the review.

Measures of treatment effect-Where meta-analyses were performed, the intervention effect was expressed as a mean difference where outcomes were reported using a standard metric (such as grams) and as a standardised mean difference where outcomes were reported using different methods or metrics of fruit and vegetable intake.

Unit of analysis issues-Cluster randomised trials in the review were assessed for unit of analysis error.

Dealing with missing data-Where available, outcomes of trials reporting an intentionto-treat analysis were reported. Sensitivity analyses to explore the impact on the overall assessment of treatment effects of the inclusion of trials not reporting an intention-to-treat analysis, with high rates of participant attrition or with other missing data, were not performed given meta-analyses were only conducted on data pooled from two trials.

Assessment of heterogeneity-Statistical heterogeneity was assessed via visual inspection of forest plots of the included trials and using the $\mathrm{I}^{2}$ statistic where data from included trials could be pooled. Examination of the trial characteristics (participants, design, interventions, outcomes and risk of bias) was also performed to identify the source of heterogeneity.

Assessment of reporting biases-Assessment of reporting bias was difficult given the heterogeneity of the included trial interventions and the limited number of included trials, precluding visual inspection of the funnel plots.

Data synthesis-Trial outcomes were assessed using a variety of dietary assessment tools and were reported in various metrics - including vitamin $\mathrm{C}$ from fruit, fruit or vegetable serves - and grams. We used fixed-effect models to perform meta-analysis. Meta-analysis was performed using the 'Review Manager' software. We did not conduct meta-analysis where a high level of heterogeneity was evident. In instances where data could not be combined in a meta-analysis, we have provided a narrative summary of the trial findings according to the review objectives.

Subgroup analysis and investigation of heterogeneity-The impact of interventions for the following subgroups were summarised narratively: 
1. interventions targeting boys and girls;

2. interventions targeting minority groups including indigenous populations;

3. interventions delivered in various settings including health and children's services;

4. interventions of varying intensities defined in terms of the number and duration of intervention contacts or components;

5. interventions delivered in different modes such as via telephone, the Internet or face-to-face.

Sensitivity analysis-Sensitivity analyses could not be conducted as meta-analysis was performed on data pooled from just two trials.

\section{RESULTS \\ Description of studies}

See: Characteristics of included studies; Characteristics of excluded studies; Characteristics of ongoing studies.

See: Characteristics of included studies; Characteristics of excluded studies; Characteristics of ongoing studies.

Results of the search-The searches generated 10,740 citations. Screening of titles and abstracts identified 145 papers for formal inclusion or exclusion. (See Figure 1). Of these, five trials (Cooke 2011; Haire-Joshu 2008; Vereecken 2009; Wardle 2003a; Watt 2009) met the inclusion criteria. All authors of included trials were contacted to provide information to facilitate assessment of risk of bias or to permit meta-analysis. All authors responded to requests for such information.

Included studies-There were 13 trial arms with 3967 participants randomised across the five included trials. A description of these trials appears in the Characteristics of included studies table. Two trials, both conducted in the UK examined the immediate or short-term (< 12 month) impact of specific feeding practices in increasing children's intake of a target vegetable (Cooke 2011; Wardle 2003a). Cooke and colleagues randomised 16 school classes of children aged four to six years to one of four conditions. First, 12 exposures over three weeks to a target vegetable coupled with a tangible non-food reward (sticker) if a child tasted the vegetable; second, exposure coupled with a social reward (praise) if a child tasted the vegetable; third, exposure alone; or fourth, a no treatment control (Cooke 2011). Intake of the target vegetable was assessed using electronic scales (grams) as part of a free-choice ad libitum consumption task at baseline, immediately post-intervention, and one and three months post-intervention.

The second UK trial randomised 156 children aged two to six years and their parents into one of three experimental conditions (Wardle 2003a) including, repeated exposure to a target vegetable over 14 consecutive days, nutrition information, and a no treatment control. Intake of the target vegetable was assessed pre-intervention and approximately two weeks 
later using electronic scales measuring the weight of vegetable on the plate before and after ad libitum consumption.

Two studies tested the impact of home visiting programs implemented in disadvantaged communities (Haire-Joshu 2008; Watt 2009). Watt and colleagues recruited 312 mothers of babies from baby clinics serving disadvantaged areas of London (Watt 2009). In addition to standard health service support, mothers were randomised to receive an intervention consisting of monthly home visits from when the infant was aged 3 to 12 months. Home visits were delivered by trained volunteers who provided practical and non-judgemental support on infant feeding practices with an emphasis on the importance of fruit and vegetable consumption. Mothers allocated to the control group received standard health professional support only (e.g. health visitors and GPs). Baseline data were collected when infants were 10 weeks old, with follow-up data collected immediately post-intervention and six months post-intervention. The primary trial outcome, vitamin $\mathrm{C}$ from fruit, was calculated as part of a multiple pass 24 hour food recall and using data from a National Nutrition Survey.

High 5 for Kids (H5-KIDS) was a USA home visiting initiative designed to increase the fruit and vegetable intake of disadvantaged children aged two to five years (Haire-Joshu 2008) enrolled in a general parenting and child development program ('Parents as Teachers'). The parent educator delivered intervention focused on parental knowledge and modelling of fruit and vegetable intake, non-coercive feeding practices and the availability of fruit and vegetables, and consisted of a tailored newsletter, four home visits, print and audiomaterials. Families allocated to the control group received only the core 'Parents as Teachers' program, consisting of home visits, on-site group activities and newsletters. Child fruit and vegetable intake was assessed via telephone using a Food Frequency Questionnaire 6 to 11 months after baseline.

One preschool-based intervention was included in the review. The Beastly Healthy at School intervention contained strategies to increase fruit and vegetable consumption targeting the child, parent and the school environment (Vereecken 2009). Children aged approximately three to five years of age attending eight Belgium preschools were randomised to receive the intervention, while children attending another eight preschools were allocated to the control. No details were provided regarding the nature of any support or any usual nutritional activities provided to control preschools. Fruit and vegetable intake was assessed using a Food Frequency Questionnaire reported by parents at a six-month follow-up for 308 and 168 children allocated to intervention and control preschools, respectively.

Excluded studies-Following an assessment of study titles and abstracts, the full texts of 145 articles were sought for further review for study eligibility (Figure 1). Of these, the eligibility of 27 trials could not be established as the study had not been published or was only a protocol $(\mathrm{N}=24)$, or could not be located $(\mathrm{N}=3)$. One hundred and seven studies were considered ineligible following the trial screening process (Reasons for exclusion included Participants $\mathrm{N}=54$; Outcomes $\mathrm{N}=24$; Comparator $\mathrm{N}=14$; Intervention $\mathrm{N}=0$; Study design $N=15$ ). Additionally, six studies (reporting the findings of five trials) were excluded at the point of data extraction given closer inspection of the eligibility criteria. 
Specifically, two studies, based on the same trial of an atherosclerosis prevention intervention, had no explicit aim to increase fruit and vegetable consumption of children despite reporting longitudinal fruit and vegetable consumption (Ruottinen 2008; Talvia 2006). A co-twin study reported by Faith and colleagues also did not aim to increase fruit and vegetable intake, rather, sought to test a methodological concept (Faith 2006). Similarly, an intervention described by Aboud and colleagues did not primarily aim to increase fruit and vegetable consumption and only assessed fruit and vegetable consumption post-hoc to describe the mechanism behind a change in weight status among study participants (Aboud 2008). Khoshnevisan and colleagues reported dietary outcomes for the intervention group only and was, therefore, excluded (Khoshnevisan 2004) and a study by Johnson and colleagues (Johnson 1993) was excluded as the outcome measure was not a quantity-based assessment of fruit and vegetable consumption.

\section{Risk of bias in included studies}

Random sequence generation-In four of the five studies, the randomisation sequence was generated by computer or random numbers tables (Cooke 2011; Haire-Joshu 2008; Vereecken 2009; Watt 2009) and the method of sequence generation in the remaining study (Wardle 2003a) was unclear.

Allocation-In two of the five studies (Wardle 2003a; Watt 2009), participant allocation was concealed from recruiters, thus representing a low risk of selection bias. The risk was unclear in two studies (Cooke 2011; Vereecken 2009), and was considered to be high in the remaining study (Haire-Joshu 2008) where recruiters were aware of participants' allocation as they were being recruited.

\section{Blinding}

Performance bias: In four of the five studies (Haire-Joshu 2008; Vereecken 2009; Wardle 2003a; Watt 2009) the intervention was delivered (at least in part) to parents who were not blinded to group allocation, and in three of these trials (Haire-Joshu 2008; Vereecken 2009; Watt 2009) parents also provided outcome data regarding their children's fruit and vegetable consumption. These three studies were determined to be at high risk of performance bias given the potential for reported trial outcomes to be influenced by the parents' knowledge of group allocation. Two trials (Cooke 2011; Wardle 2003a) used an objective outcome measure (weight of vegetable consumed as assessed by electronic scales), and as such were deemed to have a low risk of performance bias, despite those delivering the intervention being aware of participant allocation.

Detection bias: In one trial (Vereecken 2009) children's fruit and vegetable consumption was reported by parents who were not blind to group allocation, and as such there was considered to be a potentially high risk of detection bias. In the other four trials (Cooke 2011; Haire-Joshu 2008; Wardle 2003a; Watt 2009), a third party (such as a research assistant or telephone interviewer) was used to collect data regarding children's fruit and vegetable consumption. In two of these trials (Haire-Joshu 2008; Watt 2009) outcome assessors were blind to allocation, representing a low risk of detection bias, while in the other two trials (Cooke 2011; Wardle 2003a) outcomes were objectively assessed (ad 
libitum consumption of a target vegetable was measured pre- and post-intervention), and even though outcome assessors were not blind to participant allocation, the risk that detection bias would influence trial outcomes was deemed to be low.

Incomplete outcome data-All studies had data missing at follow-up. Three studies were judged to have a low risk of attrition bias (Cooke 2011; Haire-Joshu 2008; Wardle 2003a) due to high retention rates (> 80\%) which were similar across all groups. In two studies (Vereecken 2009; Watt 2009) there was judged to be a high risk of attrition bias due to high attrition rates at follow-up (Vereecken $45 \%$ to $47 \%$; Watt $30 \%$ to $34 \%$ ).

Selective reporting-One trial was prospectively registered with trial outcomes prespecified (Watt 2009) and the reported outcomes matched those in the register, representing a low risk of reporting bias. For all other trials, there was insufficient information to determine risk of bias due to selective reporting.

Other potential sources of bias-There was little evidence of unit of analysis error. All cluster randomised trials either adjusted their analyses to take the effects of clustering into account (Cooke 2011; Vereecken 2009) and/or conducted tests to determine that adjustment was not required (Cooke 2011; Haire-Joshu 2008). Details regarding such analyses are provided in the Characteristics of included studies. The study by Wardle and colleagues (Wardle 2003a) conducted analyses using all available data as well as data from only those participants in the exposure arm who received at least 10 out of a possible 14 exposures. Meta-analysis was performed on the restricted sample of participants from the exposure arm $(\mathrm{N}=34)$ as raw data for the full sample $(\mathrm{N}=48)$ was not reported. No further sources of bias could be identified.

\section{Effects of interventions}

\section{Primary outcome: Effectiveness of intervention in increasing the consumption of fruit and/or vegetables-All included trials reported the impact of} the effectiveness of the intervention on a measure of child fruit or vegetable intake. Variability in the measurement and reporting of intervention effects as change from baseline or final value scores precluded statistical examination of heterogeneity. Nonetheless, examination of the interventions tested, trial settings and study populations suggested that the included trials were heterogeneous. Therefore, meta-analyses were conducted pooling data from trials where intervention, settings and study populations were considered similar. Otherwise, we have provided a narrative synthesis of trial findings.

The effects of interventions targeting child feeding practices were mixed (Cooke 2011; Wardle 2003a). Meta-analysis of 281 participants from two trials comparing repeated food exposure alone to no treatment (Cooke 2011; Wardle 2003a) revealed no overall intervention effect at the three month post-intervention follow-up (MD 1.37, 95\% CI -2.78 to 5.52) (Analysis 1.1). The findings of the meta-analysis should be interpreted with caution as outcome data from both trials were positively skewed and were not transformed as part of pooled analyses. A single trial comparing repeated food exposures coupled with a tangible reward (sticker); or repeated food exposures coupled with a social reward (praise); with a no 
treatment control condition found significantly higher vegetable consumption (by up to approximately 30 grams) immediately post-intervention and at the one and three months post-intervention follow-up (Cooke 2011). Consumption among children in this trial receiving repeated food exposure plus tangible reward was also higher than among children receiving a repeated exposure alone immediately post-intervention and at one to three months post-intervention follow-up. Comparison between the two reward conditions revealed a significantly greater intake of the target vegetable among children receiving exposure plus tangible reward versus the exposure plus social reward immediately postintervention but not at the later follow-up.

The trial by Wardle and colleagues also tested the provision of basic nutrition information to parents in one experimental arm (Wardle 2003a). This did not significantly increase mean target vegetable consumption immediately post-intervention.

Meta-analysis pooling final outcome data ( $<12$ months post-intervention) of 1518 participants from the two home visiting intervention trials revealed no significant increase in child consumption of fruit (SMD 0.01, 95\% CI -0.09 to 0.11) (Analysis 2.1) (Haire-Joshu 2008; Watt 2009). While the trial conducted by Watt and colleagues (Watt 2009) failed to find greater consumption of vitamin $\mathrm{C}$ from fruit between groups at post-intervention assessments (the primary trial outcome), children of mothers allocated to the intervention group were more likely to consume apples, pears, boiled potatoes and carrots, but not bananas or leafy green vegetables (the secondary outcome of the trial). Similarly, the H5KIDS program found no overall increase in child intake of fruit or vegetable relative to children in the comparison condition (Haire-Joshu 2008) but did report a significant positive intervention effect (of up to one third of a serve) in a sub-group analysis of healthy weight (relative to overweight) children for combined fruit and vegetable consumption.

The Beastly Healthy at School, multi-component preschool-based intervention had a small but significant impact on child fruit consumption (Vereecken 2009). Children attending intervention preschools increased their fruit consumption by 6 grams from base-line at the six month follow-up, while fruit consumption among children in control preschools reduced by 4 grams over the same period. There were no differences between groups for vegetable consumption.

Interventions targeting boys and girls: All trials included in this review included both boys and girls. The impacts of intervention for gender subgroups were not reported in any of the included trials.

Interventions targeting minority groups and indigenous populations: Three of the included trials examined the impact of interventions on predominantly disadvantaged populations (Cooke 2011; Haire-Joshu 2008; Watt 2009). One trial recruited participants through schools where the proportion of children who had English as a second language, came from minority ethnic backgrounds or were eligible for free school meals was above average (Cooke 2011). The study demonstrated that repeated food exposure coupled with reward significantly increased the consumption of a target vegetable. Similarly, both home visiting interventions recruited participants from disadvantaged communities including 
underserved families, single or minority parent homes, or those living in poverty (HaireJoshu 2008; Watt 2009). The trials did not improve overall child fruit or vegetable intake as assessed by the primary trial outcome measures (Haire-Joshu 2008; Watt 2009).

Interventions delivered in various settings: While two of the included trials recruited study participants from preschools/schools (Cooke 2011; Vereecken 2009) only one trial assessed the impact of an intervention targeting the policies or practices of this setting. The intervention had a small but significant increase in child consumption of fruit but not vegetables (Vereecken 2009). The remaining studies were home-based interventions, of which intervention effects were mixed.

Interventions of varying intensity: In trials that incorporated home visits, the number of scheduled visits ranged from four contacts (Haire-Joshu 2008) to nine contacts (Watt 2009), with visits in both interventions lasting approximately 60 minutes. Despite the differences between the two trials in terms of intervention intensity, both studies failed to find overall positive intervention effects on the primary trial outcome. In the more intensive trial, the average number of completed visits was five (Watt 2009), whereas the intervention of lesser intensity was delivered in its entirety to $78 \%$ of participants (Haire-Joshu 2008). The two trials examining the impact of repeated food exposure were similar with regard to intensity, with Wardle and colleagues reporting a maximum of 14 exposures over consecutive days (Wardle 2003a), and Cooke and colleagues reporting a maximum of 12 exposures over consecutive school days (Cooke 2011). In the multi-component preschool-based intervention the duration or frequency of intervention contacts was not reported (Vereecken 2009).

Interventions delivered in different modalities: Three of the five trials used face-to-face intervention delivery only (Cooke 2011; Wardle 2003a; Watt 2009). The remaining two trials used face-to-face in combination with other strategies: computer-tailored newsletters and storybooks (Haire-Joshu 2008), and school-based education, training, policy and environment change (Vereecken 2009). Trials which employed face-to-face only intervention delivery formats, and those which incorporated a broader range of intervention modalities reported mixed findings in terms of intervention effects.

\section{Secondary outcome I: Cost or cost-effectiveness of interventions to increase} the consumption of fruit and/or vegetables-None of the included trials reported any information on intervention costs, or conducted cost analyses.

\section{Secondary outcome II: Adverse effects of interventions to increase the consumption of fruit and/or vegetables-None of the trials reported information} regarding any adverse events or unintended adverse consequences of the intervention.

\section{DISCUSSION}

\section{Summary of main results}

Despite the importance of encouraging fruit and vegetable consumption among children in early childhood, the review identified few randomised controlled trials of interventions 
investigating this. The included trials were heterogeneous, and collectively the findings were equivocal, providing few effective options for policy makers to improve child fruit and vegetable intake.

Two trials investigating home visiting programs provided to dis-advantaged groups did not have a clear positive intervention effect on fruit and vegetable intake immediately after the intervention or six months post-intervention (Haire-Joshu 2008; Watt 2009). A multicomponent preschool-based intervention failed to significantly increase child consumption of vegetables, but did report a small significant increase in mean child consumption of fruit six months following baseline assessment (Vereecken 2009). Two trials examining feeding strategies to encourage child consumption of a target vegetable (Cooke 2011; Wardle 2003a) indicated that repeated food exposure alone is not effective in increasing vegetable intake post-intervention. However, coupling repeated food exposure with a tangible non-food, or social reward, was effective in increasing targeted vegetable consumption in the short term ( $<$ three months post-intervention) (Cooke 2011).

\section{Overall completeness and applicability of evidence}

The paucity of published randomised trials identified in this review is surprising given efforts globally to increase fruit and vegetable intake (World Health Organization 2003). Nonetheless, previous systematic reviews of broader dietary interventions for children five years and under have similarly identified few randomised trials (Hesketh 2010). None of the included trials in this review examined long-term (> 12 months post-intervention) effects of interventions, reported cost analyses or examined any unintended adverse effects. These factors are important considerations for health practitioners and policy makers but are often not reported in randomised trials (Waters 2011) or examined in systematic reviews (Hopewell 2008; Wolfenden 2010). Furthermore, the limited number of trials identified for inclusion also prevented thorough examination of the impact of the interventions by gender, for indigenous populations, across various settings, of different intensities or delivered using various modalities. Encouragingly, a number of trial protocols (see Characteristics of ongoing studies) were identified which may address some of these gaps in the literature and are likely to be eligible for inclusion in future updates of the review. These include a multicomponent preschool-based intervention (Adams 2009), and a brief four contact telephonebased intervention delivered by trained non-health professionals (Wyse 2010).

The external validity of the review findings are limited. All trials were conducted in North America or Western Europe. None of the included trials compared participant characteristics to their sampled population and some did not specify trial inclusion or exclusion criteria (Haire-Joshu 2008; Vereecken 2009). Where recruitment was conducted via schools, clinics or Parents as Teacher programs, participation rates were generally high (> 80\%) and study attrition ranged from 12\% to 34\% (Cooke 2011; Haire-Joshu 2008; Watt 2009). With the exception of the Beastly Healthy at School study participation rates of sites subject to randomisation in cluster trials was not reported. In the Beastly Healthy at School trial the preschool participation rate was just $10 \%$ suggesting the trial findings may not generalise (Vereecken 2009). The study by Wardle and colleagues, recruited a convenience sample of 156 children and parents from a larger cohort, who had previously participated in a separate 
study, and expressed interest in future research participation (Wardle 2003a). Such participants may differ systematically to parents of children five years and under in the broader community (Trauth 2000).

\section{Quality of the evidence}

In many cases trial quality was difficult to assess given a lack of available information reported in the published manuscripts. On the basis of the information provided one of the five trials was judged to be of high methodological quality (Cooke 2011), with three studies judged to be of moderate quality (Haire-Joshu 2008; Wardle 2003a; Watt 2009), and one study judged to be of low quality (Vereecken 2009). Only one study had been prospectively registered (Watt 2009). The most significant issue affecting the quality of the included trials was the inability to blind participants to group allocation, exposing trials to performance bias which can inflate the intervention effect (Figure 2). Similarly, social desirability bias, which can also inflate intervention effects is likely within trials that did not blind participants to group allocation or use an objective outcome measure (Hebert 1995). Finally, opportunities for meta-analysis could be improved by consistent assessment measures of fruit and vegetable intake and the reporting of trial outcomes in a manner consistent with CONSORT guidelines.

\section{Potential biases in the review process}

The review employed a comprehensive and rigorous methodology including a broad search strategy, the screening of trials and extraction of data by two independent reviewers, and the appraisal of risk of bias within the included studies. Furthermore, the review did not restrict publications based on language. Two aspects of selection bias, however, are worth noting. First, we excluded trials where fruit and vegetable intake was not considered to be a primary trial outcome to avoid any potential confounding effects of other behavioural interventions (such as physical activity). This restriction may lead to over-estimates of intervention effects if in practice they are delivered in the context of other health initiatives. Second, the review included only trials which had been published in peer reviewed journals, which may also lead to overly positive estimates of intervention effects given the tendency for trials with positive findings to be more likely to be published, or published more quickly in peer reviewed journals (Higgins 2011).

\section{Agreements and disagreements with other studies or reviews}

The equivocal findings of this review regarding the impact of home visiting programs are similar to those reported in previous reviews of dietary interventions. For example, a comprehensive review of the impact of home visiting programs concluded that there was little evidence to recommend home visiting as means of improving child diet given the mixed findings of the reviewed studies (Elkan 2000). Among the trials with a positive intervention effect included in the review by Elkan and colleagues (Elkan 2000) was a pre/ post study of an intensive intervention provided to low income mothers of children aged one to four years (James 1992). In this study, dietician-trained GPs and health visitors provided advice and support as part of a primary care home visiting intervention lasting up to 20 weeks. Post-intervention improvements in diet were reported, including the consumption of fruits and vegetables. A more recent home visiting intervention (Worobey 2004) identified 
in a later review (Campbell 2007) also employed a pre/post design to examine a home visiting intervention delivered to predominantly low income Hispanic children under six years by a public health nurse. The intervention sought to improve macronutrient intake, as well as reduce high fat snack consumption and increase healthy snack consumption. Postintervention assessments found reductions in caloric intake but no change in macronutrients (Worobey 2004).

Similarly, there are few controlled trials available to put into context the mixed findings of the multi-component preschool-based intervention reported by Vereecken and colleagues (Vereecken 2009). A recent systematic review of interventions to improve diet, physical activity or prevent weight gain for children five years of age or under, and which included both randomised and non-randomised designs, identified nine studies of interventions implemented in preschool or childcare settings (Hesketh 2010). Three studies included some assessment of dietary outcome. In the first, Head Start preschools were assigned to either; a menu intervention to reduce the fat content of meals provided to children in care; the same menu intervention plus nutrition education; or a third usual care control condition (Williams 2004). Both intervention arms of the trial reduced the fat content of foods served to children relative to the preschools in the control condition. The remaining two trials assessed the impact of a healthy eating and physical activity obesity prevention program 'Hip-Hop to Health Jr', implemented in two different populations attending Head Start preschools (Fitzgibbon 2005; Fitzgibbon 2006). In one trial (Fitzgibbon 2005), intervention children reported less saturated fat intake at the one year follow-up, but not total fat or dietary fibre. No improvements in dietary intake were reported in the second trial (Fitzgibbon 2006). Nonetheless, systematic reviews of school-based fruit and vegetable interventions have frequently concluded that multi-component initiatives are effective in increasing fruit and vegetable consumption in older children, suggesting that such strategies warrant investigation in preschools (Burchett 2003; Ciliska 2000; French 2003; Knai 2006).

An early systematic review of healthy eating interventions for children aged under five years (Tedstone 1998) published by the Health Education Authority concluded that repeated food exposure is effective in enhancing children's willingness to consume novel foods provided tasting was included as a part of the exposure. Enhanced food acceptance following repeated food exposure has also been reported in other reviews and controlled trials (Contento 1995). As Cooke and colleagues point out in the background review of research for their randomised trial, evidence regarding the use of rewards to encourage child consumption of targeted foods appears more equivocal (Cooke 2011). The positive impact of both social and non-tangible rewards reported in Cooke, were, however, consistent with previous trials in community settings using tangible non-food rewards and social reward targeting the fruit or vegetable intake of school aged children (Hendy 1999).

\section{AUTHORS' CONCLUSIONS}

\section{Implications for practice}

This review provides little specific direction for health policy makers and practitioners interested in achieving increases in the fruit and vegetable consumption of children aged five 
years and under. Among those trials which significantly increased consumption, the effect sizes were small and intervention effects typically assessed only in the short term.

Notwithstanding this, a number of the intervention settings and strategies reported in the included studies have potential public health appeal. Home visiting appears to be effective in reaching disadvantaged populations, as evidenced by the high response and low attrition rates in the included home visiting studies (Haire-Joshu 2008; Watt 2009). Both studies also tested strategies which could be considered suitable for broader dissemination. In the trial by Watt and colleagues, the intervention was delivered by volunteers, a low cost approach to intervention delivery. Haire-Joshu and colleagues, incorporated the fruit and vegetable program into an existing service for disadvantaged families, a cost efficient and potentially sustainable intervention approach, which was also reported to be highly acceptable to both the parent educators who delivered the program and the parents who received it. Such findings suggest that, provided effective programs can be developed, programs delivered via home visiting may have merit in improving fruit and vegetable intake among disadvantaged families.

Findings from the two trials of feeding strategies have broad application (Cooke 2011; Wardle 2003a). The findings of one trial suggest that the pairing of repeated food exposure and a tangible non-food reward, or social reward is effective in increasing children's consumption of a target vegetable, at least in the short term. Such strategies could, therefore, be considered for inclusion in future interventions targeting children aged five years and under, across a variety of settings, particularly those targeting parent-child feeding interactions in the home.

Given the large numbers of children that attend such childcare services, and the capacity of these services to influence children's diets whilst in their care, childcare services are often advocated as important settings to improve child diet (Story 2006). While the trial by Vereeken and colleagues reported in this review significantly increased children's fruit consumption, the effect size was meagre. The authors attribute increased access to fruit at intervention preschools as primarily responsible for the intervention effect. This is consistent with previous reviews of the correlates of child fruit and vegetable intake (Blanchette 2005; Rasmussen 2006) suggesting that simply providing fruits to children whilst in care is likely to increase their consumption. Furthermore, despite parent newsletters, information evenings and other preschool-based activities, the authors suggest that greater engagement of parents may be required, a strategy also found to enhance the impact of school-based nutrition programs (Knai 2006).

Given the lack of high quality research in this area, there is considerable scope for policy makers, researchers and practitioners to develop and evaluate the impact of a variety of initiatives to improve child fruit and vegetable intake. Behavioural interventions delivered via health professionals, telephone or computer-based programs, interventions delivered through preschools, play-groups, sports clubs, or co-operatives, and those which address access issues through subsidies or other incentives all have merit, and rigorous evaluation of such interventions for children of aged five years and under would contribute greatly to the available evidence base to inform practice. As the aetiology of child diet is complex, 
interventions which target multiple determinants across a number of settings may be most likely to be effective.

\section{Implications for research}

The review identified a number of opportunities for future intervention research targeting the fruit and vegetable consumption of children aged five years and under including:

- the investigation of potential adverse effects of interventions (e.g. increased family grocery costs, or adverse effects on parent self esteem or sense of competence) as a routine part of intervention trials;

- $\quad$ examination of the cost-effectiveness of interventions found to be effective;

- interventions with extended periods of follow-up;

- $\quad$ interventions delivered using electronic modalities such as the web or smartphones;

- $\quad$ interventions implemented across a broader range of settings including heath services and sports clubs.

\section{Acknowledgments}

We would like to acknowledge the contribution of health promotion practitioners, community dieticians, Children's Services staff who provided comment on the scope and focus of the review protocol, and authors of trials who provided further information to the review team to facilitate assessments of trial eligibility and analysis. We would also like to acknowledge the assistance of the Cochrane Heart Group for executing the search and Sarah Haley who provided translation services. We would also like to acknowledge the authors of all included studies for providing additional information regarding their trials for this review.

\section{SOURCES OF SUPPORT}

Internal sources

- Hunter Medical Research Institute, Australia.

Infrastructure support

- The University of Newcastle, Australia.

Salary Support

- Deakin University, Australia.

Salary Support

- Hunter New England Area Health Service, Australia.

Salary Support

- Cancer Council NSW, Australia.

Salary Support

- Cancer Institute NSW, Australia.

Salary support

External sources

- No sources of support supplied 
CHARACTERISTICS OF STUDIES

\section{Characteristics of included studies [ordered by study ID]}

Cooke 2011

\begin{tabular}{|c|c|}
\hline Methods & Cluster randomised controlled trial \\
\hline Participants & $\begin{array}{l}\text { Description: } \\
422 \text { children in reception ( } 4 \text { to } 5 \text { years) and Year } 1 \text { ( } 5 \text { to } 6 \text { years) from } 16 \text { classes in eight schools } \\
\text { N (Randomised): } \\
16 \text { classes, } 472 \text { children } \\
\% \text { Female: } \\
47 \% \text { female } \\
\text { Age: } \\
\text { Reception: } 4 \text { to } 5 \text { years }(\mathrm{N}=216) \\
\text { Year } 1: 5 \text { to } 6 \text { years }(\mathrm{N}=206) \\
\text { SES and ethnicity: } \\
\text { "To ensure adequate representation of children from families of low socioeconomic status, we } \\
\text { selected schools in which the proportions of pupils who were eligible for free school meals, who } \\
\text { spoke English as a second language, and who came from minority ethnic backgrounds were above } \\
\text { the national average." No individual child data on these variables were reported. } \\
\text { Inclusion/exclusion criteria: } \\
\text { Not stated } \\
\text { Recruitment: } \\
\text { Recruited from } 16 \text { classes in eight schools ( } 492 \text { children, } 472 \text { consented) } \\
\text { Recruitment rate: } \\
\text { Children: } 96 \% \text { (472/492) } \\
\text { Schools: unknown } \\
\text { Region: } \\
\text { United Kingdom }\end{array}$ \\
\hline Interventions & $\begin{array}{l}\text { Number of experimental conditions: } 4 \\
\text { Number of participants (analysed): } \\
\text { Exposure + tangible non-food reward (sticker) }=99 \\
\text { Exposure + social reward (praise) }=106 \\
\text { Exposure alone }=105 \\
\text { Control = } 112 \\
\text { Description of interventions: } \\
\text { "Children in the intervention conditions (ETR, EP, EA)* were seen individually from Day } 3 \text { to Day } \\
14 \text { and offered a small piece of their target vegetable." } \\
\text { Exposure + tangible non-food reward: "Children in the ETR condition were told that if they tasted } \\
\text { the vegetable, they could choose a sticker as a reward." } \\
\text { Expoure + social reward: "Children in the EP condition were praised if they tasted the vegetable } \\
\text { (e.g. "Brilliant, you're a great taster") } \\
\text { Exposure alone: "Children in the EA condition were invited to taste the target vegetable but } \\
\text { received minimal social interaction." } \\
\text { Duration: } \\
3 \text { weeks } \\
\text { Number of contacts: } \\
12 \text { exposure sessions } \\
\text { Setting: } \\
\text { School } \\
\text { Modality: } \\
\text { Face-to-face, exposure } \\
\text { Interventionist: } \\
\text { Trained researchers } \\
\text { Integrity: } \\
\text { "Children in the three intervention groups agreed to taste their target vegetable in most sessions" } \\
\text { Exposure + tangible non-food reward (sticker): M = 11.34 sessions, SD = } 1.45 \\
\text { Exposure + social reward (praise): M = } 10.45 \text { sessions, SD = 1.94; } \\
\text { Exposure alone: M = 9.97 sessions,SD = } 2.87 . \\
\text { "Post hoc analyses showed higher compliance in the ETR condition than in the EP or EA conditions } \\
\text { (p < O.O5), and compliance in the latter two conditions did not differ." } \\
\text { Date of study: } \\
\text { Unknown } \\
\text { Description of control: } \\
\text { No treatment control: "Children in the control group did not receive taste exposure to the target } \\
\text { vegetable during the intervention period." }\end{array}$ \\
\hline
\end{tabular}

Outcomes

Outcome relating to children's fruit and vegetable consumption: 
Ad libitum consumption of target vegetable (grams). "The child was then invited to eat as much of the vegetable as he or she wanted, with intake (in grams) assessed by weighing the dish before and after consumption using a digital scale" (NB. "Care was taken to ensure that children in the ETR condition understood that the sticker reward was no longer available.")

Length of follow-up from baseline:

Acquisition data: day 15

Maintenance data: 1 month and 3 months later

Subgroup analyses:

None

Loss to follow-up (at 1 month and 3 months follow-up):

Exposure + tangible non-food reward (sticker): $7 \%, 9 \%$

Exposure + social reward (praise): $8 \%, 5 \%$

Exposure alone: $8 \%, 8 \%$

Control: $11 \%, 6 \%$

Analysis:

Analysis adjusted for clustering "Clustering by school was minimal; therefore, the final analyses adjusted only for clustering by class."

Sample size calculation was performed

Notes "On the basis of evidence that 10 exposures are needed to alter preferences, we decided to repeat all analyses for a restricted subset of children who tasted their target vegetable on at least 10 days $(n=365)$. Because there were no significant differences between the restricted and the full samples, results are reported for the full sample."

\begin{tabular}{|c|c|c|}
\hline \multicolumn{3}{|l|}{ Risk of bias } \\
\hline Bias & Authors' judgement & Support for judgement \\
\hline $\begin{array}{l}\text { Random } \\
\text { sequence } \\
\text { generation } \\
\text { (selection bias) }\end{array}$ & Low risk & $\begin{array}{l}\text { Contact with the author indicated that the study used blocked } \\
\text { randomisation performed using an online randomiser program }\end{array}$ \\
\hline $\begin{array}{l}\text { Allocation } \\
\text { concealment } \\
\text { (selection bias) }\end{array}$ & Unclear risk & $\begin{array}{l}\text { Randomisation occurred prior to consent. Head teachers were not aware of } \\
\text { group allocation. It is unclear if study personnel knew of allocation }\end{array}$ \\
\hline $\begin{array}{l}\text { Incomplete } \\
\text { outcome data } \\
\text { (attrition bias) } \\
\text { All outcomes }\end{array}$ & Low risk & $\begin{array}{l}\text { Although reasons for missing data were not provided by group, rates of } \\
\text { loss to follow up were low and similar across all experimental arms of the } \\
\text { trial at both follow-up points (Exposure+sticker }=6.5 \%, 8.8 \% \text {; Exposure } \\
+ \text { praise }=8.2 \%, 5.0 \% \text {; Exposure alone }=8.2 \%, 8.2 \% ; \text { Control }=10.9 \% \text {, } \\
5.7 \% \text {, provided by the author). No reasons were reported for loss to follow } \\
\text { up }\end{array}$ \\
\hline $\begin{array}{l}\text { Selective } \\
\text { reporting } \\
\text { (reporting bias) }\end{array}$ & Unclear risk & $\begin{array}{l}\text { Insufficient information to permit judgment } \\
\text { Trial was registered, but not prospectively (ISRCTN42922680) }\end{array}$ \\
\hline Other bias & Low risk & No further risks of bias identified \\
\hline $\begin{array}{l}\text { Blinding of } \\
\text { participants and } \\
\text { personnel } \\
\text { (performance } \\
\text { bias) } \\
\text { All outcomes }\end{array}$ & Low risk & $\begin{array}{l}\text { Contact with the author indicated that personnel were not blind to group } \\
\text { allocations and that there was the potential that participants became aware } \\
\text { of group allocation. However, given the objective outcome measure, } \\
\text { review authors judged that the outcome would not be influenced by lack of } \\
\text { blinding }\end{array}$ \\
\hline $\begin{array}{l}\text { Blinding of } \\
\text { outcome } \\
\text { assessment } \\
\text { (detection bias) } \\
\text { All outcomes }\end{array}$ & Low risk & $\begin{array}{l}\text { Contact with the author indicated that some, but not all of the outcome } \\
\text { assessors were blind to group allocation. The outcome measurement } \\
\text { (grams of target vegetable consumed, as measured by a digital scale), } \\
\text { however, was objective and unlikely to have been influenced by lack of } \\
\text { blinding }\end{array}$ \\
\hline
\end{tabular}

Haire-Joshu 2008

\begin{tabular}{ll}
\hline Methods & Cluster randomised controlled trial \\
\hline Participants & Description: \\
& Parents and their children participating in the 'Parents as Teachers' (PAT) program sites in rural \\
& Missouri (USA) \\
& N (Randomised): \\
& 16 PAT sites, 1658 families
\end{tabular}

Cochrane Database Syst Rev. Author manuscript; available in PMC 2014 September 11. 
Age:

Children:

1 to $3 \mathrm{y}$ : intervention $=67 \%$, control $=61 \%$

4 to $6 \mathrm{y}$ : intervention $=33 \%$, control $=40 \%$

Parents:

$<25 \mathrm{y}$ : intervention $=28 \%$, control $=21 \%$

25 to 29 y: intervention $=35 \%$, control $=33 \%$

30 to 34 y: intervention $=21 \%$, control $=24 \%$

$35+\mathrm{y}$ : intervention $=17 \%$, control $=23 \%$

$\%$ Female:

Children: intervention $=47 \%$, control $=49 \%$

Parents: intervention $=99 \%$, control $=98 \%$

SES and ethnicity:

Parent - Not high school graduate: intervention $=16 \%$, control $=11 \%$

Parent - College graduate: intervention $=20 \%$, control $=25 \%$

Household income:

LUSD 20K: intervention $=30 \%$, control $=25 \%$

USD $20 \mathrm{~K}$ to $35 \mathrm{~K}$ : intervention $=30 \%$, control $=25 \%$

USD $35 \mathrm{~K}$ to $50 \mathrm{~K}$ : intervention $=13 \%$, control $=18 \%$

USD 50+K: intervention $=28 \%$, control $=32 \%$

Ethnicity - White race: intervention $=86 \%$, control $=80 \%$

Inclusion/exclusion criteria:

Not specified

Recruitment:

"16 PAT programs from rural, southeast Missouri were recruited into the study. Within these sites 2012 families enrolled were assessed for eligibility and willingness to participate by parent

educators." PAT is a "parenting and child development program with over 3000 sites across all 50 states and 8 US territories." PAT provides free services on "an annual basis to parents at the time of pregnancy until the youngest child is 3 years of age. However, PAT extends services until the youngest child is 5 years of age in the case of underserved families, defined as single or minority parent homes, those living in poverty or low parent education. In addition, underserved families may receive additional home visits as a means of ensuring complete delivery of the curriculum."

Recruitment rate:

Families: $79 \%$ families

PAT sites: unknown

Region:

Rural southeast Missouri (USA)

Interventions Number of experimental conditions: 2

Number of participants (analysed):

Intervention $=605$, Control $=701$

Description of intervention:

Intervention families received the standard PAT program plus the 'Hi 5 for Kids' (H5-KIDS)

protocol. "H5-KIDS was comprised of three components: a tailored newsletter, a series of home

visits, and materials for the parent and child, including storybooks."

Computer tailored nutrition newsletter

"To develop the tailored newsletter, parents were first formally enrolled in H5-KIDS and completed a pretest interview. Relevant data was then imported into an in-house computer-based tailoring program. Scores were calculated based on FV knowledge and intake, frequency of parental modeling, style of parenting (coercive or non-coercive), and quality of the home food environment ( $F V$ availability). Each newsletter began with a bulleted tailored statement that included the self reported servings of FVs the parent and the child consumed per day. Additional parent data (e.g. FV knowledge, parental role modeling, non-coercive parenting skills, FV availability) were each uniquely used to individualize messages and describe the themes of each of the four storybook sets the family would receive at their home visits. For example, if participant data indicated a parent did not eat FV in front of their child very often ( $<7 /$ week), the tailored messages would emphasize the importance of modeling FV intake in front of the child as a means of improving consumption, and provide relevant examples of how this could be accomplished. The parent was then referred to H5KIDS storybooks that provided examples of modeling for the child. In contrast, parents who scored appropriately in each individual area received messages of praise encouraging them to continue their behaviors. Newsletters were mailed to the parent's home at the beginning of the program."

\section{Home visits}

"Parent educators delivered four H5-KIDS home visits, each of which addressed the core program areas (knowledge, parental modeling of FV intake, non-coercive feeding practices, FV availability). Parent educators then reinforced the core content in subsequent visits. Consistent with the philosophy of the PAT program, each visit provided examples of parent-child activities designed around healthy nutrition, that the parent could use to promote the child's language and cognitive ability, and bne and gross motor skill development (e.g. having the child learn the names and colors of various FV; child assists with selecting a variety of $F V$ for breakfast). As part of each visit, parents also received materials and informational handouts with suggestions for improving feeding practices and the food environment in the home. Consistent with the standard PAT program, each home visit was designed to allow for 60 min of contact."

Sing-a-long storybooks with audio cassette

"At each home visit children received a H5-KIDS sing-a-long storybook with audio cassette tape and a coloring book. Each storybook reinforced one of the core areas of the H5-KIDS program through the use of child friendly characters and appealing storylines presented through songs." 
Duration:

60 minutes per home visit

Number of contacts:

4 H5-KIDS home visits plus 5 standard PAT home visits

Setting:

The Home

Modality:

Face-to-face via home visits

Interventionist:

Parent educators who received 4 hours of training on nutrition content and overview of materials Integrity:

"The H5-KIDS program was delivered in its entirety to $78 \%$ of intervention families."

Date of study:

2001 to 2006

Description of control:

"Parent educators deliver a standardized curriculum via at least five home visits, on-site group activities and newsletters." ("PAT ... empowers parents ... by encouraging positive parent-child communication and increasing parents' knowledge of ways to stimulate children's social and physical development.")

\begin{tabular}{|c|c|c|}
\hline Outcomes & \multicolumn{2}{|c|}{$\begin{array}{l}\text { Outcome relating to children's fruit and vegetable consumption: } \\
\text { Child's daily servings of fruits and of vegetables assessed using the Saint Louis University for Kids } \\
\text { Food Frequency Questionnaire (SLU4Kids FFQ) administered via parent telephone survey } \\
\text { Length of follow-up from baseline: } \\
\text { Average time to follow-up was } 7 \text { months (range } 6 \text { to } 11 \text { months) } \\
\text { Subgroup analyses: } \\
\text { Normal weight vs overweight children } \\
\text { Loss to follow-up: } \\
\text { Intervention: } 15 \%(+5 \% \text { missing or inconsistent data) } \\
\text { Control: } 17 \% \text { ( }+5 \% \text { missing or inconsistent data) } \\
\text { Analysis: } \\
\text { Analysis was not adjusted, but justification was provided. "There was minimal impact of grouping by } \\
\text { site on the principle measures of impact in this study (ICC child fruit and vegetable servings = } \\
\text { O.O0095 and ICC parent fruit and vegetable servings }=0.01) \text {. Therefore, the analyses did not adjust } \\
\text { for group." } \\
\text { Sample size calculation was performed. }\end{array}$} \\
\hline Notes & $\begin{array}{l}\text { The proportion of norn } \\
\text { the subgroup analysis }\end{array}$ & t children not reported, making it difficult to interpret \\
\hline \multicolumn{3}{|l|}{ Risk of bias } \\
\hline Bias & Authors' judgement & Support for judgement \\
\hline $\begin{array}{l}\text { Random } \\
\text { sequence } \\
\text { generation } \\
\text { (selection } \\
\text { bias) }\end{array}$ & Low risk & $\begin{array}{l}\text { "A computer generated number table was used for } \\
\text { random assignment to intervention or control." }\end{array}$ \\
\hline $\begin{array}{l}\text { Allocation } \\
\text { concealment } \\
\text { (selection } \\
\text { bias) }\end{array}$ & High risk & $\begin{array}{l}\text { "Families enrolled in PAT were assessed for eligibility } \\
\text { and willingness to participate by parent educators." } \\
\text { Contact with the author indicated that parent educators } \\
\text { were aware of site allocation when they were enrolling } \\
\text { participants to the trial }\end{array}$ \\
\hline $\begin{array}{l}\text { Incomplete } \\
\text { outcome data } \\
\text { (attrition bias) } \\
\text { All outcomes }\end{array}$ & Low risk & $\begin{array}{l}\text { Rates of loss to follow-up (intervention }=15 \% \text {, control } \\
=17 \% \text { ) and missing/ inconsistent data (intervention }= \\
5 \%, \text { control }=5 \% \text { ) were similar across groups. No } \\
\text { information was provided about reasons for loss to } \\
\text { follow-up }\end{array}$ \\
\hline $\begin{array}{l}\text { Selective } \\
\text { reporting } \\
\text { (reporting } \\
\text { bias) }\end{array}$ & Unclear risk & $\begin{array}{l}\text { A subgroup analysis was conducted based on child's } \\
\text { weight status (normal vs overweight). "A final } \\
\text { limitation of the study is the limited power to definitely } \\
\text { assess the impact of the intervention of children within } \\
\text { weight status subgroups." It is unclear whether the } \\
\text { subgroup analysis was pre-specified }\end{array}$ \\
\hline Other bias & Low risk & $\begin{array}{l}\text { Rationale provided for not adjusting analysis for } \\
\text { clustering. "There was minimal impact of grouping by } \\
\text { site on the principle measures of impact in this study } \\
\text { (ICC child fruit and vegetable servings }=0.00095 \text { and } \\
\text { ICC parent fruit and vegetable servings }=0.01 \text { ). } \\
\text { Therefore, the analyses did not adjust for group." } \\
\text { No further risks of bias identified. }\end{array}$ \\
\hline
\end{tabular}




\begin{tabular}{lll}
$\begin{array}{l}\text { Blinding of } \\
\text { participants } \\
\text { and personnel } \\
\text { (performance }\end{array}$ & High risk & $\begin{array}{l}\text { Study personnel were aware of allocation - "Sites were } \\
\text { not blind to assignment." Contact with the author } \\
\text { indicated that parent participants completed a consent } \\
\text { bias) }\end{array}$ \\
$\begin{array}{ll}\text { All outcomes which described the activities of their } \\
\text { experimental condition, and were therefore unlikely to } \\
\text { be blind to allocation. Given the trial outcomes were } \\
\text { based on parental report, the review authors judged } \\
\text { there were potential for performance bias }\end{array}$ \\
\hline $\begin{array}{l}\text { Blinding of } \\
\text { outcome } \\
\text { assessment } \\
\text { (detection } \\
\text { bias) }\end{array}$ & Low risk & $\begin{array}{l}\text { Contact with the author indicated that outcome } \\
\text { All outcomes }\end{array}$ \\
\hline
\end{tabular}

Vereecken 2009

\begin{tabular}{|c|c|}
\hline Methods & Cluster randomised controlled trial \\
\hline Participants & $\begin{array}{l}\text { Description: } \\
\text { Children attending } 16 \text { preschools in East Flanders (Belgium) } \\
\mathbf{N} \text { (Randomised) } \\
16 \text { schools, } 1432 \text { preschoolers } \\
\text { Age: (DOB) } \\
\text { <2002: intervention }=41 \% \text {, control }=51 \% \\
2002: \text { intervention }=28 \% \text {, control }=24 \% \\
2003: \text { intervention }=31 \% \text {, control }=26 \% \\
\% \text { Female: } \\
\text { Intervention }=53 \% \text {, control }=44 \% \\
\text { SES and ethnicity: } \\
\text { Predominantly low parental education } \\
\text { Low education (mother): intervention }=49 \% \text {, control }=49 \% \\
\text { Low education (father): intervention }=60 \% \text {, control }=57 \% \\
\text { Ethnicity: No information provided } \\
\text { Inclusion/exclusion criteria: } \\
\text { Not specified } \\
\text { Recruitment: } \\
\text { Schools were approached by mail for consent. All parents of preschoolers attending the consenting } \\
\text { schools were asked to fill in a food frequency questionnaire } \\
\text { Recruitment rate: } \\
\text { Parents: } 54 \% \\
\text { Schools: } 10 \% \text { ( } 40 \text { out of } 403 \text { schools consented, although only } 8 \text { were selected in the end) } \\
\text { Region: } \\
\text { East Flanders (Belgium) }\end{array}$ \\
\hline Interventions & $\begin{array}{l}\text { Number of experimental conditions: } 2 \\
\text { Number of participants (analysed): } \\
\text { Intervention = } 308 \text {, Control = } 168 \\
\text { Description of intervention: } \\
8 \text { preschools received a multi-component intervention to assist schools to implement a healthy } \\
\text { school food policy."The main objectives were to increase the consumption of fruit, vegetables and } \\
\text { water and to decrease the consumption of sugared milk drinks and fruit juice." } \\
\text { The main strategies to influence the child and the different environmental factors included: } \\
\text { "Child: Guided and self-guided activities based on experiential education (e.g. tasting) and } \\
\text { developmental education (e.g. explanation of concepts of food triangle); Role model, feed back and } \\
\text { reinforcement by teachers; Educational role-model story and characters; Availability of healthy } \\
\text { foods; Availability of cooking equipment. } \\
\text { Parents: Newsletters; Suggestions for the back and forth diary; Work sheets and creations by } \\
\text { children; Parent evenings and other school activities with parents } \\
\text { Teacher: Training sessions; Manual including didactic and policy aspects; Digital learning } \\
\text { environment; Newsletters; Group discussions with teachers; Examples of good practices } \\
\text { School environment: Newsletters; Training sessions for principals and cafeteria staff; Help on } \\
\text { demand via e-mail; Examples of good practices; Policy aspects in the teachers' manual Feedback } \\
\text { to schools." } \\
\text { Duration: } \\
6 \text { months } \\
\text { Number of contacts: } \\
\text { Unclear (multi-component) } \\
\text { Setting: }\end{array}$ \\
\hline
\end{tabular}

Cochrane Database Syst Rev. Author manuscript; available in PMC 2014 September 11. 
Preschool

Modality:

Multiple (staff training, experiential education, newsletters, email support, resources)

Interventionist:

Not specified

Integrity:

No information provided

Date of study:

Sept 2006 - April 2007

Description of control:

8 preschools received the control: no information provided

\begin{tabular}{|c|c|c|}
\hline Outcomes & \multicolumn{2}{|c|}{$\begin{array}{l}\text { Outcome relating to children's fruit and vegetable consumption: } \\
\text { Daily consumption of fresh fruit and vegetables (grams) as reported by parents in a written food } \\
\text { frequency questionnaire } \\
\text { Length of follow-up from baseline: } \\
6 \text { months (March/April 2007) } \\
\text { Subgroup analyses: } \\
\text { None } \\
\text { Loss to follow-up } \\
\text { Intervention: } 47 \% \\
\text { Control: } 45 \% \\
\text { Analysis: } \\
\text { Contact with the author indicated that the analysis was adjusted for clustering by school } \\
\text { Unknown if sample size calculation was performed }\end{array}$} \\
\hline \multicolumn{3}{|l|}{ Notes } \\
\hline \multicolumn{3}{|l|}{ Risk of bias } \\
\hline Bias & Authors' judgement & Support for judgement \\
\hline $\begin{array}{l}\text { Random } \\
\text { sequence } \\
\text { generation } \\
\text { (selection bias) }\end{array}$ & Low risk & $\begin{array}{l}\text { Contact with the author indicated that a computerised random number } \\
\text { generator was used }\end{array}$ \\
\hline $\begin{array}{l}\text { Allocation } \\
\text { concealment } \\
\text { (selection bias) }\end{array}$ & Unclear risk & $\begin{array}{l}\text { Contact with the author indicated that schools did not know their } \\
\text { allocation prior to consenting to the study. It is unclear if study personnel } \\
\text { responsible for recruitment were aware of group allocation }\end{array}$ \\
\hline $\begin{array}{l}\text { Incomplete } \\
\text { outcome data } \\
\text { (attrition bias) } \\
\text { All outcomes }\end{array}$ & Unclear risk & $\begin{array}{l}\text { Although similar across groups (intervention }=47 \% \text {, control }=45 \% \text { ), rates } \\
\text { of loss to follow-up were high. Contact with the author indicated that no } \\
\text { information was collected on reasons for loss to follow-up }\end{array}$ \\
\hline $\begin{array}{l}\text { Selective } \\
\text { reporting } \\
\text { (reporting bias) }\end{array}$ & Unclear risk & Insufficient information to permit judgement. \\
\hline Other bias & Low risk & $\begin{array}{l}\text { Contact with the author indicated that analysis was adjusted for clustering } \\
\text { No further risk of bias identified. }\end{array}$ \\
\hline $\begin{array}{l}\text { Blinding of } \\
\text { participants and } \\
\text { personnel } \\
\text { (performance } \\
\text { bias) } \\
\text { All outcomes }\end{array}$ & High risk & $\begin{array}{l}\text { Contact with the author indicated that parents and school staff were not } \\
\text { blind to group allocation and that parents could have attended information } \\
\text { sessions organised by the researchers, or observed posters, newsletters or } \\
\text { intervention materials in intervention schools. Given that the relevant trial } \\
\text { outcomes were based on parental reports, the review authors judged that } \\
\text { there was a risk of bias }\end{array}$ \\
\hline $\begin{array}{l}\text { Blinding of } \\
\text { outcome } \\
\text { assessment } \\
\text { (detection bias) } \\
\text { All outcomes }\end{array}$ & High risk & $\begin{array}{l}\text { Contact with the author indicated that parents and school staff were not } \\
\text { blind to group allocation and that parents could have attended information } \\
\text { sessions organised by the researchers, or observed posters newsletters or } \\
\text { intervention materials in intervention schools. Given that the relevant trial } \\
\text { outcomes were based on parental reports, the review authors judged that } \\
\text { there was a risk of bias. (NB. There were no independent outcome } \\
\text { assessors in this trial, the parents completed and returned a food frequency } \\
\text { questionnaire about their child's food intake) }\end{array}$ \\
\hline
\end{tabular}

Wardle 2003a 


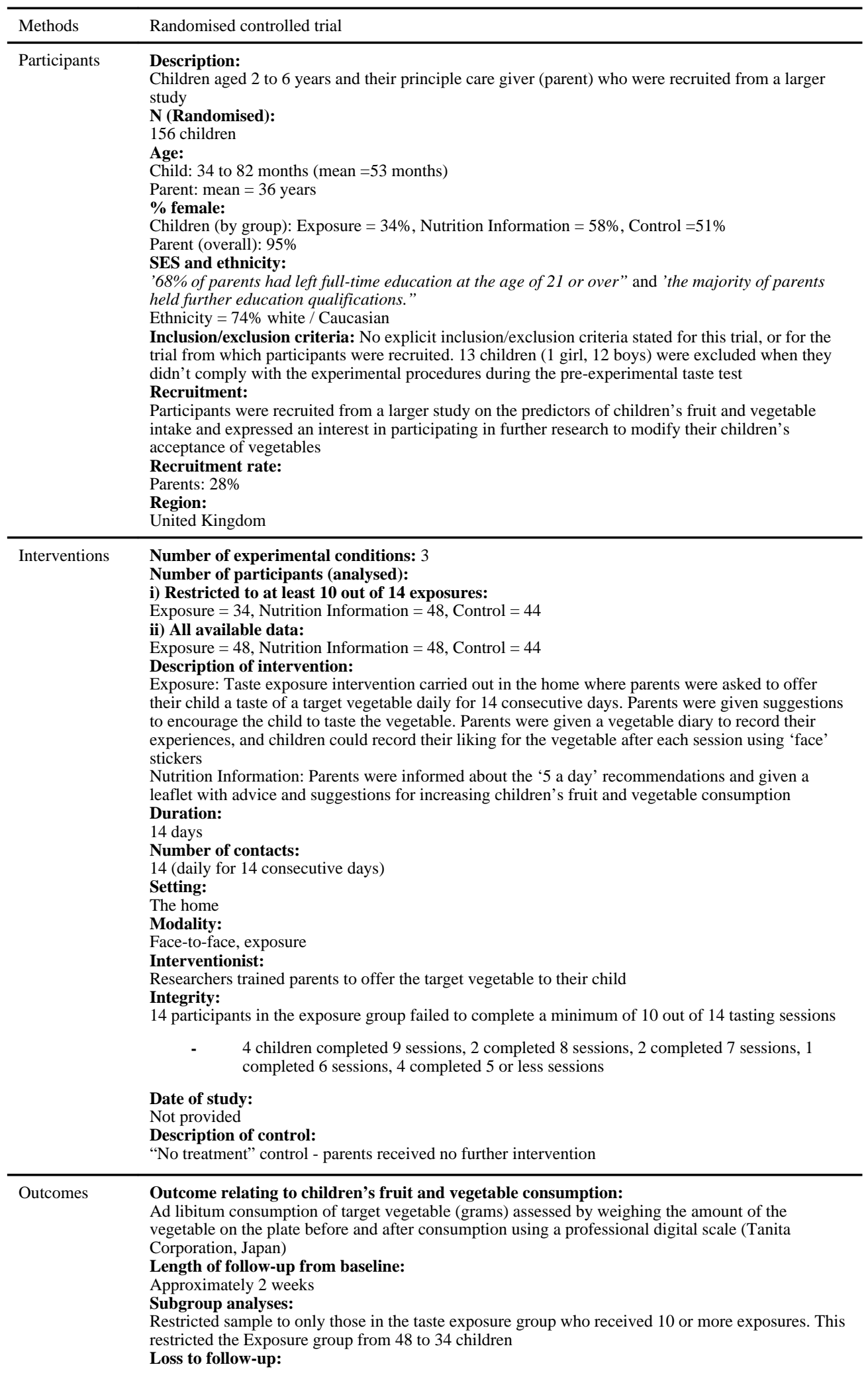


$2 \%$ (140 provided follow-up data of 143 who were eligible and provided data at baseline) Exposure: $4 \%$ (children withdrawn from their study by their parents following collection of baseline data)

Nutrition Information: 0\%

Control: $2 \%$ (children withdrawn from their study by their parents following collection of baseline data)

Analysis:

Adjustment for clustering not applicable

Unknown if sample size calculation was performed

\begin{tabular}{|c|c|c|}
\hline Notes & \multicolumn{2}{|c|}{$\begin{array}{l}\text { "Two sets of analyses were carried out: (a) on a restricted sample which excluded those in the } \\
\text { Exposure group who completed less than } 10 \text { tasting sessions }(n=126) \text { and }(b) \text { on the whole sample } \\
(n=140) \text {. Results below refer to the reduced sample size ... results for the whole sample are only } \\
\text { included where they differed from these." }\end{array}$} \\
\hline \multicolumn{3}{|l|}{ Risk of bias } \\
\hline Bias & Authors' judgement & Support for judgement \\
\hline $\begin{array}{l}\text { Random } \\
\text { sequence } \\
\text { generation } \\
\text { (selection bias) }\end{array}$ & Unclear risk & $\begin{array}{l}\text { "Participants were randomly assigned to one of three } \\
\text { experimental treatment groups". No further information } \\
\text { provided regarding sequence generation }\end{array}$ \\
\hline $\begin{array}{l}\text { Allocation } \\
\text { concealment } \\
\text { (selection bias) }\end{array}$ & Low risk & $\begin{array}{l}\text { Contact with the author indicated that allocation was } \\
\text { concealed in an opaque envelope opened at participants } \\
\text { homes after baseline data collection }\end{array}$ \\
\hline $\begin{array}{l}\text { Incomplete } \\
\text { outcome data } \\
\text { (attrition bias) } \\
\text { All outcomes }\end{array}$ & Low risk & $\begin{array}{l}\text { Rates of loss to follow-up were similar and low across the } \\
\text { exposure }(4 \%) \text {, nutrition information }(0 \%) \text { and the control } \\
\text { conditions }(2 \%) \text {. Reasons for loss to follow-up were } \\
\text { provided and were similar }\end{array}$ \\
\hline $\begin{array}{l}\text { Selective } \\
\text { reporting } \\
\text { (reporting bias) }\end{array}$ & Unclear risk & Insufficient information to permit judgement. \\
\hline Other bias & Low risk & No further risk of bias identified. \\
\hline $\begin{array}{l}\text { Blinding of } \\
\text { participants } \\
\text { and personnel } \\
\text { (performance } \\
\text { bias) } \\
\text { All outcomes }\end{array}$ & Low risk & $\begin{array}{l}\text { Contact with the author indicated that personnel } \\
\text { delivering the intervention were not blind to group } \\
\text { allocation and that parents may not have been blind to } \\
\text { group allocation. However, given the objective assessment } \\
\text { of outcome (electronic scales), the review authors judged } \\
\text { that the study outcome was unlikely to be affected by lack } \\
\text { of blinding }\end{array}$ \\
\hline $\begin{array}{l}\text { Blinding of } \\
\text { outcome } \\
\text { assessment } \\
\text { (detection bias) } \\
\text { All outcomes }\end{array}$ & Low risk & $\begin{array}{l}\text { Contact with the author indicated that the outcome } \\
\text { assessors were not blind to group allocation. Given the } \\
\text { objective measure of outcome (electronic scales) } \\
\text { assessment is unlikely to have been influenced by lack of } \\
\text { blinding }\end{array}$ \\
\hline
\end{tabular}

Watt 2009

\begin{tabular}{ll}
\hline Methods & Randomised controlled trial \\
\hline Participants & Description: \\
& New mothers attending baby clinics in disadvantaged London neighbourhoods \\
& N (Randomised): \\
& 312 mothers \\
Age: & Children: mean =10 weeks \\
& Parents: mean = 30 years \\
\% Female: \\
Children = not stated \\
Parents = 100\% \\
SES and ethnicity: \\
28\% lone parents \\
57\% living in social housing \\
33\% receiving income support/job seekers allowance \\
Ethnicity: $50 \%$ from an ethnic minority
\end{tabular}


Inclusion/exclusion criteria:

Inclusion criteria: "Women from Registrar General occupational classes II-V (non-professional); babies born >/= 37 weeks; babies' birth weight above 2500g; singletons; women able to understand written and spoken English; and resident in the study area."

Exclusion criteria: "Women aged under 17 years; infants were diagnosed with a serious medical condition or were on special diets; infants aged over 12 weeks; women or their partners were from social class I (professional). Originally their intention was to restrict the sample to first-time mothers over the initial 12 week recruitment period. The inclusion criteria was therefore changed to include all new-mothers."

\section{Recruitment:}

"Women were recruited from December 2002 to February 2004 at baby clinics located in the more disadvantaged neighbourhoods across Camden and Islington where Surestart (a national social welfare initiative targeting families with young children) programmes existed. A standardised technique was used to approach new mothers attending the baby clinics. An overview of the study was given and randomisation explained. If the women were interested, a short screening questionnaire was then used to assess their eligibility."

Recruitment rate:

Mothers: $82 \%$

Region:

London, UK

Interventions Number of experimental conditions: 2

Number of participants (analysed):

Intervention $=124$, Control $=115(12$ months $)$

Intervention $=108$, Control $=104$ (18 months)

Description of intervention:

A monthly home visiting program (from 3 to 12 months) delivered by trained local mothers,

providing practical support on infant feeding practices

Duration:

9 months (duration of each visit $=60 \mathrm{~min}$ )

Number of contacts:

Monthly from 3 to 12 months (maximum $=10$ contacts)

Setting:

The home

Modality:

Face-to-face, via home-visiting

Interventionist:

Trained local volunteers "A group of local mothers were recruited and trained to provide the support in a 12-session programme delivered over a 4-week period."

Integrity:

"On average each woman in the intervention group received five volunteer home visits (range 1-10).

A small number of women were also contacted by telephone when home visits were not possible."

Date of study:

Recruited from Dec 2002 to Feb 2004

Description of control:

Usual care. "Women in the control group only received standard professional support from health visitors and GPs."

Outcomes Outcome relating to children's fruit and vegetable consumption:

Children's intake of vitamin C from fruit

Secondary outcome: Proportion of children who consumed specific fruits and vegetables more than once a week

Length of follow-up from baseline:

42 weeks and 68 weeks (when children aged 12 months and 18 months, respectively)

Subgroup analyses:

None

Loss to follow-up: (at 12 and 18 months)

Intervention: $27 \%, 34 \%$

Control: $20 \%, 30 \%$

Analysis:

Adjustment for clustering not applicable

Sample size calculation was performed

\begin{tabular}{|c|c|c|}
\hline Notes & & \\
\hline \multicolumn{3}{|l|}{ Risk of bias } \\
\hline Bias & Authors' judgement & Support for judgement \\
\hline $\begin{array}{l}\text { Random } \\
\text { sequence } \\
\text { generation } \\
\text { (selection bias) }\end{array}$ & Low risk & $\begin{array}{l}\text { "A random allocation schedule was prepared in } \\
\text { advance using random digit computer tables." }\end{array}$ \\
\hline
\end{tabular}

Cochrane Database Syst Rev. Author manuscript; available in PMC 2014 September 11. 


\begin{tabular}{|c|c|c|}
\hline $\begin{array}{l}\text { Allocation } \\
\text { concealment } \\
\text { (selection bias) }\end{array}$ & Low risk & $\begin{array}{l}\text { "Those responsible for recruiting... were all masked } \\
\text { to group assignment." }\end{array}$ \\
\hline $\begin{array}{l}\text { Incomplete } \\
\text { outcome data } \\
\text { (attrition bias) } \\
\text { All outcomes }\end{array}$ & Unclear risk & $\begin{array}{l}\text { Rates of loss to follow-up were similar across } \\
\text { intervention }(27 \%, 34 \%) \text { and control }(20 \%, 30 \%) \\
\text { groups at both time points and were moderate. There } \\
\text { were no substantial differences in the reasons for loss } \\
\text { to follow-up }\end{array}$ \\
\hline $\begin{array}{l}\text { Selective } \\
\text { reporting } \\
\text { (reporting bias) }\end{array}$ & Low risk & $\begin{array}{l}\text { All primary or secondary outcomes of interest were } \\
\text { reported according to the information provided in the } \\
\text { trial register (ISRCTN 55500035) }\end{array}$ \\
\hline Other bias & Low risk & $\begin{array}{l}\text { Small deviation in protocol: The original sample was } \\
\text { restricted to first time mothers but after } 12 \text { weeks of } \\
\text { the } 14 \text { month recruit this was broadened to all new } \\
\text { mothers No further risks of bias identified }\end{array}$ \\
\hline $\begin{array}{l}\text { Blinding of } \\
\text { participants } \\
\text { and personnel } \\
\text { (performance } \\
\text { bias) } \\
\text { All outcomes }\end{array}$ & High risk & $\begin{array}{l}\text { Contact with the author indicated that parent } \\
\text { participants and intervention personnel were not blind } \\
\text { to group allocation. Given that the trial outcome was } \\
\text { based on parental reports of children's fruit intake the } \\
\text { reviewers judged that there was a risk of performance } \\
\text { bias in this study }\end{array}$ \\
\hline $\begin{array}{l}\text { Blinding of } \\
\text { outcome } \\
\text { assessment } \\
\text { (detection bias) } \\
\text { All outcomes }\end{array}$ & Low risk & $\begin{array}{l}\text { "Those responsible for... assessing outcomes were all } \\
\text { masked to group assignment." }\end{array}$ \\
\hline
\end{tabular}

\section{Characteristics of excluded studies [ordered by study ID]}

\begin{tabular}{ll}
\hline Study & Reason for exclusion \\
\hline Aboud 2008 & $\begin{array}{l}\text { This responsive feeding was ineligible as its primary aim was not to increase fruit and } \\
\text { vegetable consumption and the study only assessed children's fruit and vegetable } \\
\text { consumption post-hoc in order to describe the mechanism behind a change in weight status } \\
\text { among participants in the sample }\end{array}$ \\
\hline Alford 1971 & Children aged 6 to 17 years. \\
\hline Anliker 1993 & Children aged 14 to 17 years. \\
\hline Bammann 2006 & No comparison group. \\
\hline Bannon 2006 & Outcome is food choice (apple or crackers) \\
\hline Baranowski 2002 & Children aged 9 to 18 years. \\
\hline Bayer 2009 & Child mean age 6 years. \\
\hline Benjamin 2008 & Outcome is quality of meals. \\
\hline Berhe 1997 & No comparison group. \\
\hline Blom-Hoffman 2008 & Child mean age 6.2 years. \\
\hline Boaz 1998 & Children aged 7 to 9 years. \\
\hline Bollella 1999 & Outcome is vitamins and minerals, not fruit and vegetable consumption \\
\hline Briefel 2006 & No comparison group. \\
\hline Briefel 2009 & Children aged 6 to 18 years. \\
\hline Briley 1999 & No comparison group. \\
\hline Bruening 1999 & Non-equivalent control group design. \\
\hline
\end{tabular}

Cochrane Database Syst Rev. Author manuscript; available in PMC 2014 September 11. 


\begin{tabular}{|c|c|}
\hline Study & Reason for exclusion \\
\hline Byrne 2002 & Outcome is willingness to taste kohlrabi. \\
\hline Ciampolini 1991 & No comparison group. \\
\hline Coleman 2005 & No fruit and vegetable outcomes. \\
\hline Condrasky 2006 & $\begin{array}{l}\text { Quasi-experimental: intervention sample randomly selected from one church. Control } \\
\text { randomly selected from a separate church }\end{array}$ \\
\hline Court 1977 & No participants, these are guidelines, not research trial. \\
\hline de Pee 1998 & No comparison group. \\
\hline de Silva-Sanigorski 2010 & Quasi-experimental, repeat cross-sectional design. \\
\hline Dixon 1997 & Child mean age 6 years. \\
\hline Dixon 2000 & Children aged 6.3 to 6.8 years. \\
\hline Eicholzer-Helbling 1986 & Outcome no consumption measure \\
\hline Epstein 2001 & Children aged 6 to 11 years. \\
\hline Estabrooks 2009 & Children aged 8 to 12 years. \\
\hline Evans 2006 & Children in 4th, 5th grade school. \\
\hline Faber 2002 & Cross-sectional survey. \\
\hline Faith 2006 & $\begin{array}{l}\text { The intervention programme was not specifically designed to increase consumption of fruit } \\
\text { and vegetables, instead primary aim is to illustrate a methodological concept. "This } \\
\text { methodological note illustrates the use of co-twin design for testing substitution, } \\
\text { phenomenon, a prominent behavioural economics concept. We test whether fruits and } \\
\text { vegetables can substitute for high-fat snack foods in young children in a single meal } \\
\text { laboratory setting." }\end{array}$ \\
\hline Fitzgibbon 2002 & Outcome is weight change. \\
\hline Fletcher 2009 & Children aged 13 to 19 years. \\
\hline Foerster 1998 & Children in 4th, 5th grade school. \\
\hline Folta 2006 & Children in kindergarten to grade 8 school. \\
\hline Freedman 2010 & Outcome is child feeding attitudes and practices. \\
\hline Gentile 2009 & Children in 3rd, 4th, 5th grade school. \\
\hline Gittelsohn 2010 & Children aged 8 to 12 years. \\
\hline Goldberg 2009 & Children in grades 1 to 3 school. \\
\hline Gosliner 2010 & $\begin{array}{l}\text { Quasi-experimental: child care centres in existing study matched to other child care centres, } \\
\text { then randomised }\end{array}$ \\
\hline Gottesman 2003 & No participants, not research trial. \\
\hline Gottesman 2007 & No participants, not research trial \\
\hline Graham 2008 & Outcome no fruit and vegetable consumption. \\
\hline Gratton 2007 & Children aged 11 to 16 years. \\
\hline Hambleton 2004 & Children aged 9 to 10 years. \\
\hline Havas 1997 & No assessments of children included in study. \\
\hline Heim 2009 & Children in 4th and 6th grade school \\
\hline Hendy 2002 & No comparison group. \\
\hline Hildebrand 2010 & No comparison group \\
\hline Horne 2009 & Child mean age 7 years. \\
\hline Horodynski 2004 & Non-equivalent control group study design. \\
\hline
\end{tabular}

Cochrane Database Syst Rev. Author manuscript; available in PMC 2014 September 11. 


\begin{tabular}{|c|c|}
\hline Study & Reason for exclusion \\
\hline Horodynski 2005 & Outcome is feeding behaviours. \\
\hline Hu 2010 & Outcome is eating behaviours and weight, not fruit and vegetables \\
\hline Hughes 2007 & Outcome is feeding styles and behaviour. \\
\hline IFIC 2002 & Children aged 9 to 12 years \\
\hline James 1992 & No comparison group. \\
\hline Jayne 2009 & Outcome is food choice. \\
\hline Johnson 1993 & $\begin{array}{l}\text { This study was excluded as fruit and vegetable consumption was measured in terms of } \\
\text { dietitian-classified 'appropriate' versus 'inappropriate' consumption levels, and as such, it } \\
\text { failed to meet the inclusion criteria relating to the primary outcome }\end{array}$ \\
\hline Johnson 2007 & Outcome is food preference and ranking. \\
\hline Kalb 2005 & No participants, not research trial. \\
\hline Kashani 1991 & Child mean age 10 years. \\
\hline Kelder 1995 & Children in 6th grade school. \\
\hline Khoshnevisan 2004 & $\begin{array}{l}\text { Dietary outcomes are not reported for the control group and no comparison is made } \\
\text { between between experimental conditions }\end{array}$ \\
\hline Kidala 2000 & Quasi-experimental: 2 areas, 1 intervention, 1 control, not randomly selected \\
\hline Kilaru 2005 & Outcome is proportion being fed bananas. \\
\hline Korwanich 2008 & Quasi-experimental: 8 intervention schools; 8 matched control schools \\
\hline LaRowe 2010 & No comparison group \\
\hline Leahy 2008 & No fruit and vegetable outcome. \\
\hline Locard 1987 & No comparison group. \\
\hline Low 2007 & $\begin{array}{l}\text { Quasi-experimental, } 2 \text { intervention areas, and } 1 \text { control area selected, in prospective } \\
\text { longitudinal study }\end{array}$ \\
\hline Luepker 1996 & Child mean age 8.8 years. \\
\hline Malekafzali 2000 & No fruit and vegetable consumption data. \\
\hline Manios 2009 & No comparison group. \\
\hline Martens 2008 & Children aged 12 to 14 years. \\
\hline McAuley 2010 & Child mean age 7.7 years. \\
\hline McKenzie 1996 & Child mean age 6.3 to 6.8 years. \\
\hline NAPNAP 2006 & Guidelines not trial, so no participants. \\
\hline Nemet 2007 & Child mean age 5.5 years. \\
\hline Nemet 2008 & Children aged 8 to 11 years. \\
\hline Niederer 2009 & Child mean age 5.1 years. \\
\hline Noller 2006 & Outcome is public health impact, not fruit and vegetable consumption \\
\hline O’Connor 2010 & No comparison group. \\
\hline Olvera 2010 & Children aged 7 to 13 years. \\
\hline Panunzio 2007 & Children in 4th grade school. \\
\hline Parcel 1989 & Children in 3rd, 4th grade school. \\
\hline Passehl 2004 & Outcome is process evaluation. \\
\hline Perry 1985 & Children in 3rd, 4th grade school. \\
\hline Perry 1998 & Child mean age 8.8 years. \\
\hline
\end{tabular}

Cochrane Database Syst Rev. Author manuscript; available in PMC 2014 September 11. 


\begin{tabular}{|c|c|}
\hline Study & Reason for exclusion \\
\hline Rahman 1994 & Outcome asks if vegetables eaten today (Yes/No). No amount provided \\
\hline Ransley 2007 & Non-randomised controlled trial. 1 intervention sample and 1 matched control sample \\
\hline Reinaerts 2007 & $\begin{array}{l}\text { Quasi-experimental: consenting schools paired then randomised to one of two } \\
\text { interventions. Control schools in different area identified and then matched }\end{array}$ \\
\hline Reinaerts 2008 & Child mean age 8 years. \\
\hline Reverdy 2008 & Children aged 8 to 10 years. \\
\hline Ruottinen 2008 & $\begin{array}{l}\text { The intervention programme was not specifically designed to increase consumption of fruit } \\
\text { and vegetables } \\
\text { The aim of intervention, as reported in a separate paper (Lapinleimu 1995) is "to } \\
\text { investigate the effects of an individually supervised, eucaloric, diet with low content of fat, } \\
\text { saturated fat and cholesterol in healthy children" }\end{array}$ \\
\hline Salminen 2005 & Children aged 6 to 17 years. \\
\hline Sanigorski 2008 & Child mean age 8 years. \\
\hline Schwartz 2007a & Study design uses convenience sample. \\
\hline Schwartz 2007b & $\begin{array}{l}\text { Quasi-experimental - } 2 \text { elementary schools randomly allocated to } 1 \text { intervention and } 1 \\
\text { control }\end{array}$ \\
\hline Siega-Riz 2004 & No comparison group. \\
\hline Simons-Morton 1988 & Children in 3rd, 4th grade school. \\
\hline Solomons 1999 & Review, not trial, no participants. \\
\hline Sweitzer 2010 & Outcome is servings packed in lunchbox, not consumed. \\
\hline Talvia 2006 & $\begin{array}{l}\text { The intervention programme was not specifically designed to increase consumption of fruit } \\
\text { and vegetables } \\
\text { The aim of intervention, as reported in a separate paper (Lapinleimu 1995) is "to } \\
\text { investigate the effects of an individually supervised, eucaloric, diet with low content off at, } \\
\text { saturated fat and cholesterol in healthy children" }\end{array}$ \\
\hline Taylor 2007 & Child mean age 7.7 years. \\
\hline Uicab-Pool 2009 & Outcome is eating habits. \\
\hline Van Horn 2005 & Children aged 8 to 10 years. \\
\hline Vecchiarelli 2005 & Children school-aged. \\
\hline Veldhuis 2009 & Outcome is weight, not fruit and vegetable consumption. \\
\hline Wardle $2003 b$ & Child mean age 6 years. \\
\hline Whaley 2010 & Study design in intervention and matched control site. \\
\hline Winkler 2005 & Outcome is education program evaluation. \\
\hline Zotor 2008 & Children aged 11 to 15 years. \\
\hline
\end{tabular}

\section{Characteristics of ongoing studies [ordered by study ID]}

Adams 2009

\begin{tabular}{ll}
\hline Trial name or title & Tooty Fruity Vegie Program \\
\hline Methods & Cluster randomised study with pre- and post-intervention evaluation (non-randomised controls) \\
\hline Participants & Preschoolers attending 18 interventions and 13 control preschools in NSW (Australia) \\
\hline Interventions & $\begin{array}{l}\text { Interventions: "The intervention strategies included skill development and awareness-raising for } \\
\text { parents, staff and children, and social support for parents to foster behaviour change in their }\end{array}$
\end{tabular}

Cochrane Database Syst Rev. Author manuscript; available in PMC 2014 September 11. 
children through feedback and reinforcement (positive feedback and policies on food and drinks at preschool). Project management committees (PMCs), with parents, staff and health professionals in each preschool, oversaw strategy implementation and ensured sustainability of the program after the one-year supported intervention. " Control: Received the intervention after one year.

Outcomes Consumption of fruit and vegetables collected from a parent survey

- $\quad$ Fruit serves eaten yesterday

- $\quad$ Occasions child ate legumes or vegetables yesterday.

\begin{tabular}{ll}
\hline Starting date & 2006 \\
\hline Contact information & Jillian Adams (jillian.adams@ncahs.health.nsw.gov.au) \\
\hline Notes & \\
\hline
\end{tabular}

Campbell 2008

\begin{tabular}{ll}
\hline Trial name or title & INFANT - The Infant Feeding Activity and Nutrition Trial \\
\hline Methods & Cluster randomised controlled trial \\
\hline Participants & $\begin{array}{l}\text { Approx } 600 \text { members of first time parents groups at maternal and child health centres within } 12 \\
\text { LGAs.* }\end{array}$ \\
\hline Interventions & $\begin{array}{l}\text { Intervention: "The intervention will be delivered by a dietitian and is comprised of six sessions } \\
\text { delivered at three month intervals during the regular meeting time of the first-time parents' } \\
\text { group (see Table 1). Based on an anticipatory guidance framework the intervention will } \\
\text { incorporate a range of modes of delivery and educational strategies including brief didactic } \\
\text { sessions, use of group discussion and peer support, exploration of perceived barriers, use of } \\
\text { visual and written messages, follow-up delivery of messages by text-messaging and mail-outs. } \\
\text { All educational concepts will be developed iteratively, that is, messages will be repeated and } \\
\text { expanded upon over the course of the intervention." } \\
\text { Control: "The control group families will receive usual care from their MCH nurse. In addition, } \\
\text { these families will be sent general health newsletters (e.g. dental health, sun protective } \\
\text { behaviours, general safety), and will receive Birthday and Christmas cards. These families' } \\
\text { participation will be rewarded with gifts (to a maximum value of \$15.00) on receipt of } \\
\text { completed questionnaires." }\end{array}$ \\
\hline Outcomes & $\begin{array}{l}\text { Child's dietary intake will be assessed by telephone administered multi-pass 24-hour recall with } \\
\text { parents }\end{array}$ \\
\hline Starting date & Unknown \\
\hline Contact information & Zoe McCallum (Zoe.mccallum @ rch.org.au) \\
\hline Notes & \\
\hline
\end{tabular}

Daniels 2009

\begin{tabular}{ll}
\hline Trial name or title & NOURISH trial \\
\hline Methods & Randomised controlled trial \\
\hline Participants & $\begin{array}{l}\text { Approx } 820 \text { first time mothers (at least } 18 \text { years old) delivering healthy (> 2500 g), term }(>35 \\
\text { weeks) infants at public maternity hospitals in Brisbane }(\mathrm{N}=3) \text { and Adelaide }(\mathrm{N}=3)(\text { Australia) } \\
\text { over a consecutive } 4 \text { month period (with full enrolment to the study to commence when the } \\
\text { infant is } 4 \text { to } 7 \text { months). Mothers must be willing to attend sessions at designated metropolitan } \\
\text { child health clinics }\end{array}$ \\
\hline Interventions & $\begin{array}{l}\text { Intervention: Fortnightly group sessions delivered at existing child health clinics. Group sessions } \\
\text { with } 10 \text { to } 15 \text { mothers per group. Sessions delivered by a dietitian and psychologist with } \\
\text { paediatric experience. Six fortnightly sessions (4 to } 7 \text { months), then } 6 \text { fortnightly sessions (13 to } \\
\text { 16 months) then monthly maintenance contacts for } 6 \text { months, plus a workbook and fridge }\end{array}$
\end{tabular}

Cochrane Database Syst Rev. Author manuscript; available in PMC 2014 September 11. 
magnet with the key messages from each module Control: Self-directed access to 'usual' child health services at child health clinics

\begin{tabular}{ll} 
& $\begin{array}{l}\text { magnet with the key messages from each module Control: Self-directed access to 'usual' child } \\
\text { health services at child health clinics }\end{array}$ \\
\hline Outcomes & $\begin{array}{l}\text { Infant intake (variety and frequency) of fruits and vegetables. Assessed at baseline and follow- } \\
\text { up ( } 9 \text { and } 18 \text { months) from food intake records from } 3 \text { non-consecutive days (include a weekend } \\
\text { day) using } 2 \times 24 \mathrm{~h} \text { food records plus telephone } 24 \mathrm{~h} \text { recall }\end{array}$ \\
\hline Starting date & Unknown \\
\hline Contact information & Lynne Daniels (12daniels@qut.edu.au) \\
\hline Notes & \\
\hline
\end{tabular}

Wen 2007

\begin{tabular}{ll}
\hline Trial name or title & Healthy Beginnings Trial \\
\hline Methods & Randomised controlled trial \\
\hline Participants & $\begin{array}{l}\text { Approx 782 first time mothers (aged 16 years and older) recruited from all pregnant women } \\
\text { attending antenatal classes at Liverpool and Campbelltown hospitals (Australia) }\end{array}$ \\
\hline Interventions & $\begin{array}{l}\text { Intervention: Intensive, home-based, early intervention delivered by a specialist trained nurse - 8 } \\
\text { visits over the first 2 years of life, plus proactive telephone support, promoting healthy feeding } \\
\text { and physical activity and enhanced parent / child interaction } \\
\text { Control: Usual care (current standard practice includes one home visit by a community nurse } \\
\text { within one month of birth and possible baby clinic visits, plus home safety materials) }\end{array}$ \\
\hline Outcomes & $\begin{array}{l}\text { Intake at fruit and vegetables at age 2 years. (Phase 2: Intake of fruit and vegetables at age 3, 4 } \\
\text { \& 5 years). } \\
\text { Measured in participant's homes. (The nutrition measures are currently being validated in a }\end{array}$ \\
\hline sample of 2 to 4 year olds, plus questions regarding food habits from existing population health \\
surveys)
\end{tabular}

Wyse 2010

\begin{tabular}{ll}
\hline Trial name or title & The Healthy Habits trial \\
\hline Methods & Cluster randomised controlled trial \\
\hline Participants & $\begin{array}{l}\text { Parents of } 3 \text { to } 5 \text { year old children from randomly selected preschools in the Hunter Region of } \\
\text { NSW Australia }\end{array}$ \\
\hline Interventions & $\begin{array}{l}\text { Intervention: } 4 \times \text { weekly } 30 \text { minute telephone support calls to increase the availability and } \\
\text { accessibility of fruit and vegetables in the home, create supportive family eating routines and } \\
\text { role-model fruit and vegetable consumption } \\
\text { Control: Print resources }\end{array}$ \\
\hline Outcomes & $\begin{array}{l}\text { Children's fruit and vegetable consumption as measured by the Fruit and Vegetable subscale of } \\
\text { the Children's Dietary Questionnaire administered via telephone at 2, 6, 12 and 18 months }\end{array}$ \\
\hline Starting date & Unknown \\
\hline Contact information & Rebecca Wyse (rebecca.wyse@ hnehealth.nsw.gov.au) \\
\hline Notes & \\
\hline LGA = Local Government Area
\end{tabular}

Cochrane Database Syst Rev. Author manuscript; available in PMC 2014 September 11. 


\section{DATA AND ANALYSES}

\begin{tabular}{|c|c|c|c|c|}
\hline \multicolumn{5}{|c|}{$\begin{array}{l}\text { Comparison } 1 \\
\text { Short term impact }(<12 \text { months) of repeated exposure } \\
\text { intervention versus no intervention on child } \\
\text { consumption of a target vegetable }\end{array}$} \\
\hline $\begin{array}{l}\text { Outcome or subgroup } \\
\text { title }\end{array}$ & No. of studies & No. of participants & Statistical method & Effect size \\
\hline 1 Vegetable intake (g) & 2 & 281 & $\begin{array}{l}\text { Mean Difference (IV, Fixed, } \\
95 \% \text { CI) }\end{array}$ & $1.37[-2.78,5.52]$ \\
\hline
\end{tabular}

Comparison 2

Short term impact (< 12 months) of home visiting intervention versus usual care

\begin{tabular}{lcccc}
\hline $\begin{array}{l}\text { Outcome or } \\
\text { subgroup title }\end{array}$ & No. of studies & No. of participants & Statistical method & Effect size \\
\hline 1 Fruit intake & 2 & 1518 & $\begin{array}{l}\text { Std. Mean Difference (IV, } \\
\text { Fixed, 95\% CI) }\end{array}$ & $0.01[-0.09,0.11]$ \\
\hline
\end{tabular}

\section{Analysis 1.1}

Comparison 1 Short term impact ( $<12$ months) of repeated exposure intervention versus no intervention on child consumption of a target vegetable, Outcome 1 Vegetable intake $(g)$

Review: Interventions for increasing fruit and vegetable consumption in children aged 5 years and under Comparison: 1 Short term impact ( $<12$ months) of repeated exposure intervention versus no intervention on child consumption of a target vegetable

Outcome: 1 Vegetable intake (g)

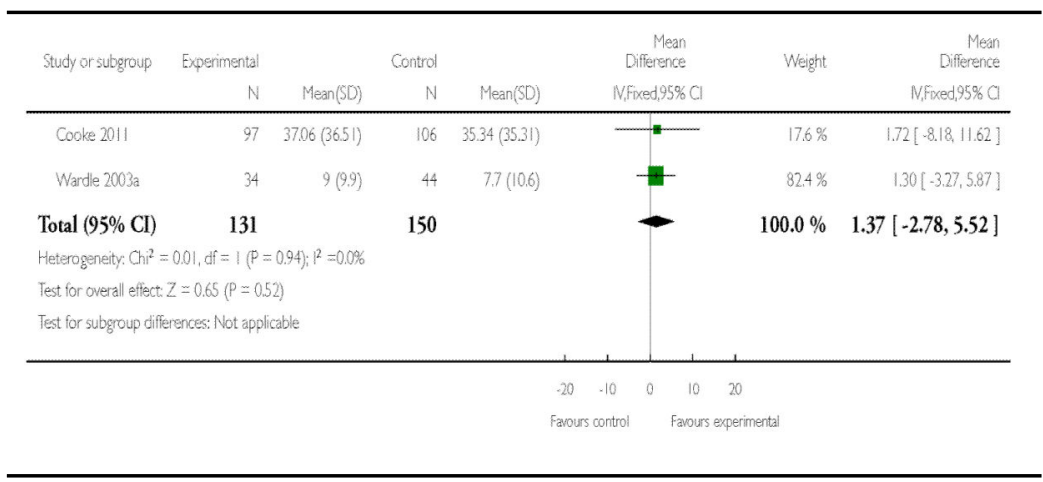




\section{Analysis 2.1}

Comparison 2 Short term impact (< 12 months) of home visiting intervention versus usual care., Outcome 1

Fruit intake

Review: Interventions for increasing fruit and vegetable consumption in children aged 5 years and under

Comparison: 2 Short term impact ( $<12$ months) of home visiting intervention versus usual care.

Outcome: 1 Fruit intake

\begin{tabular}{|c|c|c|c|c|c|c|c|}
\hline \multirow[t]{2}{*}{ Study or subgroup } & \multirow{2}{*}{$\begin{array}{r}\text { Experimental } \\
\mathrm{N}\end{array}$} & \multicolumn{2}{|r|}{ Control (usual care) } & & $\begin{array}{r}\text { Std. } \\
\text { Mean } \\
\text { Difference }\end{array}$ & \multirow[t]{2}{*}{ Weight } & \multirow{2}{*}{$\begin{array}{r}\text { Std. } \\
\text { Mean } \\
\text { Difference } \\
\text { MVFived, }, 5 \% \text { O }\end{array}$} \\
\hline & & $\operatorname{Mean}(S D)$ & N & $\operatorname{Mean}(S D)$ & N,Fixed, $95 \%$ & & \\
\hline Haire-Joshu 2008 & 605 & $0.03(1.61)$ & 701 & $0.01(1.39)$ & E & $860 \%$ & $0.03[-0.08,0.14]$ \\
\hline Watt 2009 & 104 & $19.9(19.3)$ & 108 & $21.4(18)$ & $\rightarrow$ & $14.0 \%$ & $-0.08[-0.35,0.19]$ \\
\hline Total $(95 \% \mathrm{Cl})$ & 709 & & 809 & & - & $100.0 \%$ & $0.01[-0.09,0.11]$ \\
\hline \multicolumn{8}{|c|}{ Heterogeneity $G \mathrm{Ch}^{2}=0.52, \mathrm{df}=1(\mathrm{P}=0.47) ; 2^{2}=0.0 \%$} \\
\hline \multicolumn{8}{|c|}{ Test for overall effect: $Z=0.23(P=0.82)$} \\
\hline \multicolumn{8}{|c|}{ Test for subgroup differences: Not applicable } \\
\hline \multicolumn{8}{|c|}{ 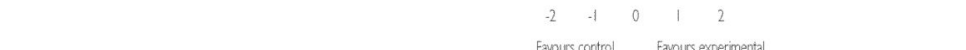 } \\
\hline & & & & & control Fanot & ermental & \\
\hline
\end{tabular}

\section{Appendix 1. Search strategies}

\section{CENTRAL in The Cochrane Library}

\#1 MeSH descriptor Fruit explode all trees

\#2 MeSH descriptor Citrus explode all trees

\#3 MeSH descriptor Vegetables explode all trees

\#4 fruit* in All Text

\#5 vegetable* in All Text

\#6 orange* in All Text

\#7 apple* in All Text

\#8 (pear in All Text or pears in All Text)

\#9 (grape in All Text or grapes in All Text)

\#10 banana* in All Text

\#11 (berry in Title, Abstract or Keywords or berries in Title, Abstract or Keywords)

$\# 12$ citrus in All Text

\#13 carrot* in All Text

\#14 "greens" in All Text 


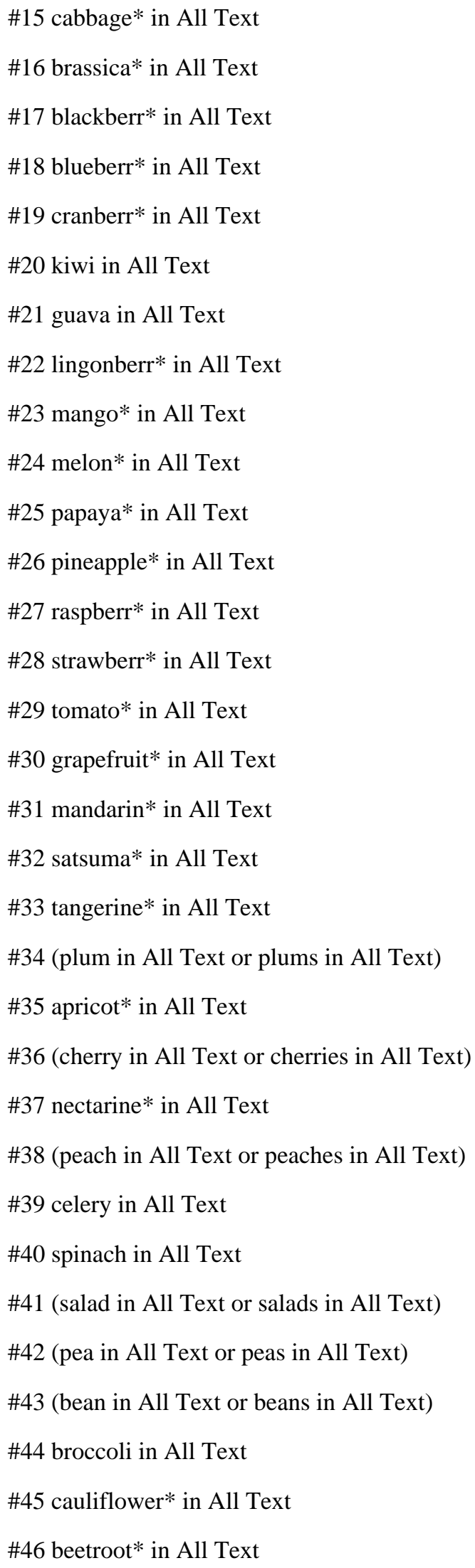


\#47 turnip* in All Text

\#48 rhubarb in All Text

\#49 MeSH descriptor Food Habits this term only

\#50 MeSH descriptor Food Preferences this term only

\#51 healthy next eating in All Text 208

$\# 52$ (\#1 or \#2 or \#3 or \#4 or \#5 or \#6 or \#7 or \#8 or \#9 or \#10)

$\# 53$ (\#11 or \#12 or \#13 or \#14 or \#15 or \#16 or \#17 or \#18 or \#19 or \#20)

$\# 54$ (\#21 or \#12 or \#23 or \#24 or \#25 or \#26 or \#27 or \#28 or \#29 or \#30)

$\# 55$ (\#31 or \#32 or \#33 or \#34 or \#35 or \#36 or \#37 or \#38 or \#39 or \#40)

$\# 56$ (\#41 or \#42 or \#43 or \#44 or \#45 or \#46 or \#47 or \#48 or \#49 or \#50 or \#51)

$\# 57$ (\#52 or \#53 or \#54 or \#55 or \#56)

\#58 MeSH descriptor Health Education explode all trees

\#59 MeSH descriptor Health Promotion explode all trees

\#60 MeSH descriptor behavior therapy explode all trees

\#61 MeSH descriptor counseling explode all trees

\#62 MeSH descriptor organizational policy this term only

\#63 (public in All Text and policy in All Text)

\#64 MeSH descriptor public policy this term only

\#65 MeSH descriptor health policy explode all trees

\#66 MeSH descriptor inservice training explode all trees

\#67 promot* in All Text

\#68 educat* in All Text

\#69 program* in All Text

\#70 (policy in All Text or policies in All Text)

\#71 train* in All Text

\#72 (diet* in All Text near/6 intervention* in All Text)

\#73 (behavi* in All Text near/6 intervention* in All Text)

$\# 74$ (\#58 or \#59 or \#60 or \#61 or \#62 or \#63 or \#64 or \#65 or \#66 or \#67)

$\# 75$ (\#68 or \#69 or \#70 or \#71 or \#72 or \#73 or \#74)

\#76 (\#74 or \#75)

\#77 MeSH check word Infant

\#78 MeSH descriptor Child, Preschool this term only 
\#79 (child in All Text or children in All Text)

\#80 (pre-school* in All Text or preschool* in All Text)

\#81 (infant in All Text or infants in All Text)

\#82 (nursery in All Text or nurseries in All Text)

\#83 MeSH descriptor Parents explode all trees

\#84 (parent in All Text or parents in All Text)

\#85 toddler* in All Text

\#86 MeSH descriptor Nurseries this term only

\#87 nurseries in All Text

$\# 88$ (\#77 or \#78 or \#79 or \#80 or \#81 or \#82 or \#83 or \#84 or \#85 or \#86 or \#87)

\#89 (\#57 and \#76 and \#88)

\section{MEDLINE OVID}

1. exp Fruit/

2. exp Citrus/

3. exp Vegetables/

4. fruit*.tw.

5. vegetable*.tw.

6. orange*.tw.

7. apple*.tw.

8. (pear or pears).tw.

9. (grape or grapes).tw.

10. banana*.tw.

11. (berry or berries).tw.

12. citrus.tw.

13. carrot*.tw.

14. greens.tw.

15. cabbage*.tw.

16. brassica*.tw.

17. blackberr*.tw.

18. blueberr*.tw.

19. cranberr*.tw.

20. guava*.tw. 
21. kiwi*.tw.

22. lingonberr*.tw.

23. mango*.tw.

24. melon*.tw.

25. papaya*.tw.

26. pineapple*.tw.

27. raspberr*.tw.

28. strawberr*.tw.

29. tomato*.tw.

30. potato*.tw.

31. onion*.tw.

32. grapefruit*.tw.

33. mandarin*.tw.

34. satsuma*.tw.

35. tangerine*.tw.

36. (plum or plums).tw.

37. apricot*.tw.

38. (cherry or cherries).tw.

39. nectarine*.tw.

40. (peach or peaches).tw.

41. celery.tw.

42. spinach*.tw.

43. (salad or salads).tw.

44. (pea or peas).tw.

45. (bean or beans).tw.

46. broccoli.tw.

47. cauliflower*.tw.

48. beetroot*.tw.

49. turnip*.tw.

50. rhubarb.tw

51. Food Habits/

52. Food Preferences/ 
53. ((food or eating) adj (habit* or preference*)).tw.

54. eating behavi*.tw.

55. (health* adj eating).tw.

56. or $/ 1-55$

57. exp Health Education/

58. exp Health Promotion/

59. $\exp$ Behavior Therapy/

60. exp Counseling/

61. organizational policy/

62. Public Policy/

63. exp Health Policy/

64. exp Inservice Training/

65. promot*.tw.

66. educat*.tw.

67. program*.tw.

68. (policy or policies).tw.

69. train*.tw.

70. (diet* adj6 intervention*).tw.

71. (behavi* adj6 intervention*).tw.

72. or $/ 57-71$

73. exp Infant/

74. Child, Preschool/

75. (child or children).tw.

76. (pre-school* or preschool*).tw.

77. (infant or infants).tw.

78. infancy.tw.

79. (nursery or nurseries).tw.

80. exp Parents/

81. (parent or parents).tw.

82. toddler*.tw.

83. Nurseries/

84. (baby or babies).tw. 
85. or $/ 73-84$

86. 56 and 72 and 85

87. randomized controlled trial.pt.

88. controlled clinical trial.pt.

89. randomized.ab.

90. placebo.ab.

91. drug therapy.fs.

92. randomly.ab.

93. trial.ab.

94. groups.ab.

95. 87 or 88 or 89 or 90 or 91 or 92 or 93 or 94

96. exp animals/ not humans.sh.

97. 95 not 96

98. 86 and 97

\section{EMBASE Classic + EMBASE (OVID)}

1. exp Fruit/

2. exp Vegetables/

3. fruit*.tw.

4. vegetable*.tw.

5. orange*.tw.

6. apple*.tw.

7. (pear or pears).tw.

8. (grape or grapes).tw.

9. banana*.tw.

10. (berry or berries).tw.

11. citrus.tw.

12. carrot*.tw.

13. greens.tw.

14. cabbage*.tw.

15. brassica*.tw.

16. blackberr*.tw.

17. blueberr*.tw. 
18. cranberr*.tw.

19. guava*.tw.

20. kiwi*.tw.

21. lingonberr*.tw.

22. mango*.tw.

23. melon*.tw.

24. papaya*.tw.

25. pineapple*.tw.

26. raspberr*.tw.

27. strawberr*.tw.

28. tomato* tw.

29. grapefruit*.tw.

30. mandarin*.tw.

31. satsuma*.tw.

32. tangerine*.tw.

33. (plum or plums).tw.

34. apricot*.tw.

35. (cherry or cherries).tw.

36. nectarine*.tw.

37. (peach or peaches).tw.

38. celery.tw.

39. spinach*.tw.

40. (salad or salads).tw.

41. (pea or peas).tw.

42. (bean or beans).tw.

43. onion*.tw.

44. broccoli.tw.

45. cauliflower*.tw.

46. beetroot*.tw.

47. turnip*.tw.

48. rhubarb.tw.

49. potato*.tw. 
50. exp feeding behavior/

51. ((food or eating) adj (habit* or preference*)).tw.

52. eating behavi*.tw.

53. (health* adj eating).tw.

54. or $/ 1-53$

55. exp health education/

56. consumer health information/

57. behavior therapy/

58. exp counseling/

59. policy/

60. health care policy/

61. in service training/

62. promot*.tw.

63. educat*.tw.

64. program*.tw.

65. (policy or policies).tw.

66. train*.tw.

67. (diet* adj6 intervention*).tw.

68. (behavi* adj6 intervention*).tw.

69. lifestyle modification/

70. or $/ 55-69$

71. exp infant/

72. preschool child/

73. (child or children).tw.

74. (pre-school* or preschool*).tw.

75. (infant or infants).tw.

76. infancy.tw.

77. (nursery or nurseries).tw.

78. exp parent/

79. (parent or parents).tw.

80. toddler/

81. toddler*.tw. 
82. nursery/

83. kindergarten/

84. (baby or babies).tw.

85. or/71-84

86. 54 and 70 and 85

87. random $\$$.tw.

88. factorial\$.tw.

89. crossover\$.tw.

90. cross over\$.tw.

91. cross-over\$.tw.

92. placebo\$.tw.

93. (doubl\$ adj blind $\$$ ).tw.

94. (singl\$ adj blind $\$$ ).tw.

95. assign\$.tw.

96. allocat\$.tw.

97. volunteer\$.tw.

98. crossover procedure/

99. double blind procedure/

100. randomized controlled trial/

101.single blind procedure/

102.87 or 88 or 89 or 90 or 91 or 92 or 93 or 94 or 95 or 96 or 97 or 98 or 99 or 100 or 101

103. (animal/ or nonhuman/) not human/

104. 102 not 103

$\mathbf{1 0 5 . 8 6}$ and 104

\section{PsycINFO (OVID)}
1. fruit*.tw.
2. vegetable*.tw.
3. orange*.tw.
4. apple*.tw.
5. (pear or pears).tw.
6. (grape or grapes).tw. 
7. banana*.tw.

8. (berry or berries).tw.

9. citrus.tw.

10. carrot*.tw.

11. greens.tw.

12. cabbage*.tw.

13. brassica*.tw.

14. blackberr*.tw.

15. blueberr*.tw.

16. cranberr*.tw.

17. guava*.tw.

18. kiwi*.tw.

19. lingonberr*.tw.

20. mango* $\cdot$ tw.

21. melon*.tw.

22. papaya*.tw.

23. pineapple*.tw.

24. raspberr*.tw.

25. strawberr*.tw.

26. tomato* tw.

27. grapefruit*.tw.

28. mandarin*.tw.

29. satsuma*.tw.

30. tangerine* ${ }^{*}$ tw.

31. (plum or plums).tw.

32. apricot*.tw.

33. (cherry or cherries).tw.

34. nectarine*.tw.

35. (peach or peaches).tw.

36. celery.tw.

37. spinach*.tw.

38. (salad or salads).tw. 
39. (pea or peas).tw.

40. (bean or beans).tw.

41. broccoli.tw.

42. cauliflower*.tw.

43. beetroot*.tw.

44. turnip*.tw.

45. rhubarb.tw.

46. onion*.tw.

47. potato*.tw.

48. eating behavior/

49. food preferences/

50. eating attitudes/

51. (health* adj eating).tw.

52. eating behavi*.tw.

53. ((food or eating) adj (habit* or preference*)).tw.

54. or $/ 1-53$

55. health education/

56. health promotion/

57. health literacy/

58. lifestyle changes/

59. exp behavior therapy/

60. $\exp$ counseling/

61. organizational policy/

62. exp policy making/

63. exp inservice training/

64. promot*.tw.

65. educat*.tw.

66. $\operatorname{program}^{*}$.tw.

67. (policy or policies).tw.

68. train*.tw.

69. (diet* adj6 intervention*).tw.

70. (behavi* adj6 intervention*).tw. 
71. or $/ 55-70$

72. (child or children).tw.

73. (pre-school* or preschool*).tw.

74. (infant or infants).tw.

75. (nursery or nurseries or kindergarten*).tw.

76. (parent or parents).tw.

77. toddler*.tw.

78. (baby or babies).tw.

79. exp parents/

80. exp nursery school students/

81. kindergarten students/

82. infancy.tw.

83. ("120" or " $140 "$ or " $160 ")$.ag.

84. or $/ 72-83$

85. 54 and 71 and 84

86. random $\$$.tw.

87. factorial\$.tw.

88. crossover\$.tw

89. cross-over\$.tw.

90. placebo\$.tw.

91. (doubl\$ adj blind\$).tw.

92. (singl\$ adj blind\$).tw.

93. assign\$.tw.

94. allocat\$.tw.

95. volunteer\$.tw.

96. control*.tw.

97. “2000”.md.

98. or/86-97

99. 85 and 98

\section{CINAHL Plus with Full Text}

S102 S83 and S101 
$\mathrm{S} 101 \mathrm{~S} 84$ or $\mathrm{S} 85$ or $\mathrm{S} 86$ or $\mathrm{S} 87$ or $\mathrm{S} 88$ or $\mathrm{S} 89$ or $\mathrm{S} 90$ or $\mathrm{S} 91$ or $\mathrm{S} 92$ or $\mathrm{S} 93$ or $\mathrm{S} 94$ or $\mathrm{S} 95$ or $\mathrm{S} 96$ or $\mathrm{S} 97$ or $\mathrm{S} 98$ or $\mathrm{S} 99$ or $\mathrm{S} 100$

S100 TX cross-over*

S99 TX crossover*

S98 TX volunteer*

S97 (MH “Crossover Design”)

S96 TX allocat*

S95 TX control*

S94 TX assign*

S93 TX placebo*

S92 (MH "Placebos")

S91 TX random*

S90 TX (doubl* N1 mask*)

S89 TX (singl* N1 mask*)

S88 TX (doubl* N1 blind*)

S87 TX (singl* N1 blind*)

S86 TX (clinic* N1 trial?)

S85 PT clinical trial

S84 (MH "Clinical Trials+")

S83 S55 and S69 and S82

$\mathrm{S} 82 \mathrm{~S} 70$ or S71 or S72 or S73 or S74 or S75 or S76 or S77 or S78 or S79 or S80 or S81

S81 TI kindergarten or AB kindergarten

S80 (MH “Schools, Nursery")

S79 TI (baby or babies) or AB (baby or babies)

S78 TI toddler* or AB toddler*

S77 TI (parent or parents) or AB (parent or parents)

S76 (MH "Parents+")

S75 TI (nursery or nurseries) or AB (nursery or nurseries)

S74 TI (infant or infants or infancy) or AB (infant or infants or infancy)

S73 TI (pre-school* or preschool* or "pre school*") or AB (pre-school* or preschool* or "pre school*")

S72 TI (child or children) or AB (child or children) 
S71 (MH “Child, Preschool”)

S70 (MH “Infant+")

S69 S56 or S57 or S58 or S59 or S60 or S61 or S62 or S63 or S64 or S65 or S66 or S67 or $\mathrm{S} 68$

S68 TI (behavi* N5 intervention*) or AB (behavi* N5 intervention*)

S67 TI (diet* N5 intervention*) or AB (diet* N5 intervention*)

S66 TI train* or AB train*

S65 TI (policy or policies) or AB (policy or policies)

S64 TI program* or AB program*

S63 TI educat* or AB educat*

S62 TI promot* or AB promot*

S61 (MH "Public Policy+")

S60 (MH "Organizational Policies+")

S59 (MH “Counseling+”)

S58 (MH "Behavior Therapy+")

S57 (MH "Health Promotion+")

S56 (MH "Health Education+")

$\mathrm{S} 55 \mathrm{~S} 1$ or $\mathrm{S} 2$ or $\mathrm{S} 3$ or $\mathrm{S} 4$ or $\mathrm{S} 5$ or $\mathrm{S} 6$ or $\mathrm{S} 7$ or $\mathrm{S} 8$ or $\mathrm{S} 9$ or $\mathrm{S} 10$ or $\mathrm{S} 11$ or $\mathrm{S} 12$ or $\mathrm{S} 13$ or $\mathrm{S} 14$ or $\mathrm{S} 15$ or $\mathrm{S} 16$ or $\mathrm{S} 17$ or $\mathrm{S} 18$ or $\mathrm{S} 19$ or $\mathrm{S} 20$ or $\mathrm{S} 21$ or $\mathrm{S} 22$ or $\mathrm{S} 23$ or $\mathrm{S} 24$ or $\mathrm{S} 25$ or $\mathrm{S} 26$ or S27 or S28 or S29 or S30 or S31 or S32 or S33 or S34 or S35 or S36 or S37 or $\mathrm{S} 38$ or S39 or S40 or S41 or S42 or S43 or S44 or S45 or S46 or S47 or S48 or S49 or $\mathrm{S} 50$ or $\mathrm{S} 51$ or S52 or S53 or S54

S54 TI ("food habit*" or "food preference*" or "eating habit*" or "eating preference*”) or AB ("food habit*" or "food preference*" or "eating habit*" or "eating preference*")

S53 TI "health* eating" or AB "health* eating"

S52 (MH "Food Preferences")

S51 (MH "Food Habits")

S50 TI rhubarb or AB rhubarb

S49 TI onion* or AB onion*

S48 TI potato* or AB potato*

S47 TI turnip* or AB turnip*

S46 TI beetroot* or AB beetroot*

S45 TI cauliflower* or AB cauliflower* 
S44 TI broccoli or AB broccoli

S43 TI (bean or beans) or AB (bean or beans)

S42 TI (pea or peas) or AB (pea or peas)

S41 TI (salad or salads) or AB (salad or salads)

S40 TI spinach* or AB spinach*

S39 TI celery or AB celery

S38 TI (peach or peaches) or $\mathrm{AB}$ (peach or peaches)

S37 TI nectarine* or AB nectarine*

S36 TI (cherry or cherries) or AB (cherry or cherries)

S35 TI apricot* or AB apricot*

S34 TI (plum or plums) or AB (plum or plums)

S33 TI tangerine* or AB tangerine*

S32 TI satsuma* or AB satsuma*

S31 TI mandarin* or AB mandarin*

S30 TI grapefruit* or AB grapefruit*

S29 TI tomato* or AB tomato*

S28 TI strawberr* or AB strawberr*

S27 TI raspberr* or AB raspberr*

S26 TI pineapple* or AB pineapple*

S25 TI papaya* or AB papaya*

S24 TI melon* or AB melon*

S23 TI mango* or AB mango*

S22 TI lingonberr* or AB lingonberr*

S21 TI guava* or AB guava*

S20 TI kiwi* or AB kiwi*

S19 TI cranberr* or AB cranberr*

S18 TI blueberr* or AB blueberr*

S17 TI blackberr* or AB blackberr*

S16 TI brassica* or AB brassica*

S15 TI cabbage* or AB cabbage*

S14 TI "greens" or AB "greens"

S13 TI carrot* or AB carrot* 
S12 TI citrus or $\mathrm{AB}$ citrus

S11 TI (berry or berries) or AB (berry or berries)

S10 TI banana* or AB banana*

S9 TI (grape or grapes) or AB (grape or grapes)

S8 TI (pear or pears) or AB (pear or pears)

S7 TI apple* or AB apple*

S6 TI orange* or $\mathrm{AB}$ orange*

S5 TI vegetable* or AB vegetable*

S4 TI fruit* or AB fruit*

S3 (MH "Vegetables+")

S2 (MH "Citrus+")

S1 (MH "Fruit+")

metaRegister of clinical trials

(fruit or citrus or vegetable or food habits or food preferences) AND (infant or child, preschool or parents or nurser*)

\section{WHO International Clinical Trials Registry Platform}

fruit or citrus or vegetable or food habits or food preferences AND infant or child, preschool or parents or nurser*

\section{Proquest Dissertations \& Theses}

(fruit or citrus or vegetable or food habits or food preferences) AND (infant or child, preschool or parents or nurser*)

\section{HISTORY}

Protocol first published: Issue 6, 2010

Review first published: Issue 11, 2012

\section{DIFFERENCES BETWEEN PROTOCOL AND REVIEW}

- Trials were only included if fruit and/or vegetable intake was listed as the primary trial outcome. The protocol stated that trials listing fruit and/or vegetable intake as a secondary trial outcome would also be included.

- Classification of intervention effects as 'short-term' was amended from 3 to $<12$ months in the protocol to $<12$ months in the review. 
- Professional associations were not contacted as part of the review search strategy, nor was the National Institute of Health Randomized Trial Records Database.

- Unpublished manuscripts were excluded from the review.

- The title and text throughout the review were amended to ensure consistent terminology regarding the description of age. Specifically, we replaced the age description of children as 'preschool' with a more precise description of 'children aged five years and under' to more accurately reflect the scope of the review. We refer only to preschools when discussing the findings of trials conducted in that setting specifically.

- As some trials included children across a range of ages, we included any trial where the mean age of the sample at baseline was five years or under.

- While two independent reviewers extracted data from each study, the role of the second independent reviewer was shared by two authors (BB and EJ).

\section{References to studies included in this review}

Cooke 2011 \{published data only . Cooke LJ, Chambers LC, Anez EV, Croker HA, Boniface D, Yeomans MR, et al. Eating for Pleasure or Profit: The effect of incentives on children's enjoyment of vegetables. Psychological Science. 2011; 22(2):190-6. [PubMed: 21191095]

Haire-Joshu 2008 \{published data only\} . Haire-Joshu D, Elliott MB, Caito NM, Hessler K, Nanney MS, Hale N, et al. High 5 for Kids: The impact of a home visiting program on fruit and vegetable intake of parents and their preschool children. Preventive Medicine. 2008; 47:77-82. [PubMed: 18486203]

Vereecken 2009 \{published data only\} . Vereecken C, Huybrechts I, van Houte H, Martens V, Wittebroodt I, Maes L. Results from a dietary intervention study in preschools "Beastly Healthy at School". International Journal of Public Health. 2009; 54:142-9. [PubMed: 19296055]

Wardle 2003a \{published data only\} . Wardle J, Cooke LJ, Gibson EL, Sapochnik M, Sheiman A, Lawson M. Increasing children's acceptance of vegetables; a randomized trial of parent-led exposure. Appetite. 2003; 40:155-62. [PubMed: 12781165]

Watt 2009 \{published data only\} . Watt RG, Tull KI, Wiggins M, Kelly Y, Molloy B, Dowler E, et al. Effectiveness of a social support intervention of infant feeding practices: randomised controlled trial. Journal of Epidemiology \& Community Health. 2009; 63:156-62. [PubMed: 19141661]

\section{References to studies excluded from this review}

Aboud FE, Moore AC, Akhter S. Effectiveness of a community-based responsive feeding programme in rural Bangladesh: a cluster randomized field trial. Maternal and Child Nutrition. 2008; 4:275-86. [PubMed: 18811792]

Alford 1971 \{published data only\}. Alford BB, Tibbets MH. Education increases consumption of vegetables by children. Journal of Nutrition Education. 1971; 3(7):12-4.

Anliker 1993 \{published data only\} . Anliker JA, Drake LT, Pacholski J, Little W. Impacts of a multi-layered nutrition education program: teenagers teaching children. Journal of Nutrition Education. 1993; 25(3):140-3.

Bammann 2006 \{published data only\} . Bammann K, Peplies J, Sjostrom M, Lissner L, De Henauw S, Galli C, et al. Assessment of diet, physical activity and biological, social and environmental factors in a multi-centre European project on diet- and lifestyle-related disorders in children (IDEFICS). Journal of Public Health. 2006; 14:279-89.

Bannon 2006 \{published data only\} . Bannon K, Schwartz MB. Impact of nutrition messages on children's food choice: Pilot study. Appetite. 2006; 46:124-9. [PubMed: 16442667] 
Baranowski 2002 \{published data only\} . Baranowski T, Baranowski J, Cullen KW, deMoor C, Rittenberry L, Hebert D, et al. 5 a day achievement badge for African-American boy scouts: Pilot outcome results. Preventive Medicine. 2002; 34:353-63. [PubMed: 11902852]

Bayer 2009 \{published data only\} . Bayer O, van Kries R, Strauss A, Mitschek C, Toschke AM, Hose A, et al. Short- and mid-term effects of a setting based prevention program to reduce obesity risk factors in children: A cluster-randomized trial. Clinical Nutrition. 2009; 28:122-8. [PubMed: 19303675]

Benjamin 2008 \{published data only\} . Benjamin SE, Haines J, Ball SC, Ward DS. Improving nutrition and physical activity in child care: what parents recommend. Journal of the American Dietetic Association. 2008; 108:1907-11. [PubMed: 18954582]

Berhe 1997 \{published data only\} . Berhe G. Tulimbe Nutrition Project: a community-based dietary intervention to combat micronutrient malnutrition in rural southern Malawi. SCN news. Dec.1997 (15):25-6. [PubMed: 12293177]

Blom-Hoffman 2008 \{published data only\} . Blom-Hoffman J, Wilcox KR, Dunn L, Leff SS, Power TJ. Family involvement in school-based health promotion: bringing nutrition information home. School Psychology Review. 2008; 37(4):567-77. [PubMed: 19633724]

Boaz 1998 \{published data only\} . Boaz A, Ziebland S, Wyke S, Walker J. A 'five-a-day' fruit and vegetable pack for primary school children. Part II: controlled evaluation into Scottish schools. Health Education Journal. 1998; 57:105-16.

Bollella 1999 \{published data only\} . Bollella MC, Spark A, Boccia LA, Nicklas TA, Pittman BP, Williams CL. Nutrient intake of head start children: home vs school. Journal of the American College of Nutrition. 1999; 18(2):108-14. [PubMed: 10204825]

Briefel 2006 \{published data only\} . Briefel R, Hanson C, Fox MK, Novak T, Ziegler P. Feeding infants and toddlers study: do vitamin and mineral supplements contribute to nutrient adequacy or excess among US infants and toddlers? Journal of the American Dietetic Association. 2006; 106:S52-S65. [PubMed: 16376630]

Briefel 2009 \{published data only\} . Briefel RR, Crepinsek MK, Cabili C, Wilson A, Gleason PM. School food environments and practices affect dietary behaviors of US public school children. Journal of the American Dietetic Association. 2009; 109:S91-S107. [PubMed: 19166677]

Briley 1999 \{published data only\} . Briley ME, Jastrow S, Vickers J, Roberts-Gray C. Dietary intake at child-care centers and away: Are parents and child care providers working as partners or at cross-purposes? Journal of the American Dietetic Association. 1999; 99:950-4. [PubMed: 10450310]

Bruening 1999 \{published data only\} . Bruening KS, Gilbride JA, Passannante MR, McClowry S. Dietary intake and health outcomes among young children attending 2 urban day-care centers. Journal of the American Dietetic Association. 1999; 99:1529-35. [PubMed: 10608946]

Byrne 2002 \{published data only\} . Byrne E, Nitzke S. Preschool children's acceptance of a novel vegetable following exposure to messages in a storybook. Journal of Nutrition Education and Behavior. 2002; 34:211-4. [PubMed: 12217264]

Ciampolini 1991 \{published data only\} . Ciampolini M, Vicarelli D, Bini S. Choices at weaning: main factor in ingestive behavior. Nutrition. 1991; 7:51-4. [PubMed: 1802186]

Coleman 2005 \{published data only\} . Coleman G, Horodynski MA, Contreras D, Hoerr SM. Nutrition education aimed at toddlers (NEAT) curriculum. Journal of Nutrition Education and Behavior. 2005; 37:96-7. [PubMed: 15882487]

Condrasky 2006 \{published data only\} . Condrasky M, Graham K, Kamp J. Cooking with a chef: an innovative program to improve mealtime practices and eating behaviors of caregivers of preschool children. Journal of Nutrition Education and Behavior. 2006; 38:324-5. [PubMed: 16966056]

Court 1977 \{published data only\} . Court JM. Obesity in childhood. The Medical Journal of Australia. 1977; 1:888-91. [PubMed: 887018]

de Pee 1998 \{published data only\} . de Pee S, Bloem MW, Satoto, Yip R, Sukaton A, Tjiong R, et al. Impact of a social marketing campaign promoting dark-green leafy vegetables and eggs in Central Java, Indonesia. International Journal of Vitamin and Nutrient Research. 1998; 68:38998. 
de Silva-Sanigorski 2010 \{published data only\} . de Silva-Sanigorski AM, Bell AC, Kremer P, Nichols M, Crellin M, Smith M, et al. Reducing obesity in early childhood: results from Romp \& Chomp, an Australian community-wide intervention program. American Journal of Clinical Nutrition. 2010; 91:831-40. [PubMed: 20147472]

Dixon 1997 \{published data only\} . Dixon LB, McKenzie J, Shannon BM, Mitchell DC, Smiciklas-Wright H, Tershakovec AM. The effect of changes in dietary fat on the food group and nutrient intake of 4- to 10-year-old children. Pediatrics. 1997; 100(5):863-72. [PubMed: 9346988]

Dixon 2000 \{published data only . Dixon LB, Tershakovec AM, McKenzie J, Shannon B. Diet quality of young children who received nutrition education promoting lower dietary fat. Public Health Nutrition. 2000; 3(4):411-6. [PubMed: 11135795]

Eicholzer-Helbling 1986 \{published data only\} . Eicholzer-Helbling M, Ritzel G, AckermannLiebrich U, Bachlin A, Muhlemann R. Nutrition education in kindergarten: results of an intervention study [Ernahrungserziehung im Kindergarten: Resultate einer interventionsstudie]. Sozial- und Praventivmedizin. 1986; 31(4-5):233-5. [PubMed: 3765873]

Epstein 2001 \{published data only\} . Epstein LH, Gordy CC, Raynor HA, Beddome M, Kilanowski CK, Paluch R. Increasing fruit and vegetable intake and decreasing fat and sugar intake in families at risk for childhood obesity. Obesity Research. 2001; 9(3):171-8. [PubMed: 11323442]

Estabrooks 2009 \{published data only\} . Estabrooks PA, Shoup JA, Gattshall M, Dandamudi P, Shetterly S, Xu S. Automated telephone counseling for parents of overweight children. A randomized controlled trial. American Journal of Preventive Medicine. 2009; 36(1):35-42. [PubMed: 19095163]

Evans 2006 \{published data only\} . Evans AE, Dave J, Tanner A, Duhe S, Condrasky M, Wilson $\mathrm{D}$, et al. Changing the home nutrition environment. Effects of a nutrition and media literacy pilot intervention. Family and Community Health. 2005; 29(1):43-54. [PubMed: 16340677]

Faber 2002 \{published data only\} . Faber M, Phungula MAS, Venter SL, Dhansay MA, Spinnler Benade AJ. Home gardens focusing on the production of yellow and dark-green leafy vegetables increases the serum retinol concentrations of 2-5-y-old children in South Africa. American Journal of Clinical Nutrition. 2002; 76(5):1048-54. [PubMed: 12399277]

Faith 2006 \{published data only\} . Faith MS, Rose E, Matz PE, Pietrobelli A, Epstein LH. Co-twin control designs for testing behavioral economic theories of child nutrition: methodological note. International Journal of Obesity. 2006; 30:1501-5. [PubMed: 16801929]

Fitzgibbon 2002 \{published data only\} . Fitzgibbon ML, Stolley MR, Dyer AR, VanHorn L, Kaufer Christoffel K. A community-based obesity prevention program for minority children: rationale and study design for Hip-Hop to Health Jr. Preventive Medicine. 2002; 34:289-97. [PubMed: 11817926]

Fletcher 2009 \{published data only . Fletcher A, Cooper JR, Helms P, Northington L, Winter K. Stemming the tide of childhood obesity in an underserved urban African American population: a pilot study. The ABNF Journal. 2009; 20(2):44. [PubMed: 19489282]

Foerster 1998 \{published data only\} . Foerster SB, Gregson J, Beall DL, Hudes M, Magnuson H, Livingston S, et al. The California Children's 5 a day-power play! campaign: evaluation of a large-scale social marketing initiative. Family and Community Health. 1998; 21(1):46-64.

Folta 2006 \{published data only\} . Folta SC, Goldberg JP, Economos C, Bell R, Landers S, Hyatt R. Assessing the use of school public address systems to deliver nutrition messages to children: shape up Somerville - audio adventures. The Journal of School Health. 2006; 76(9):459-64. [PubMed: 17026639]

Freedman 2010 \{published data only . Freedman MR, Alvarez KP. Early childhood feeding: assessing knowledge, attitude, and practices of multi-ethnic child-care providers. Journal of the American Dietetic Association. 2010; 110:447-51. [PubMed: 20184996]

Gentile 2009 \{published data only\} . Gentile DA, Welk G, Eisenmann JC, Reimer RA, Walsh DA, Russell DW, et al. Evaluation of a multiple ecological level child obesity prevention program: Switch ${ }^{\circledR}$ what you Do, View, and Chew. BMC Medicine. 2009; 7:49. [PubMed: 19765270]

Gittelsohn 2010 \{published data only\} . Gittelsohn J, Vijayadeva V, Davison N, Ramirez V, Cheung LWK, Murphy S, et al. A food store intervention trial improves caregiver psychosocial 
factors and children's dietary intake in Hawaii. Obesity. 2010; 18(1):S84-S90. [PubMed: 20107467]

Goldberg 2009 \{published data only\} . Goldberg JP, Collins JJ, Folta SC, McLarney MJ, Kozower C, Kuder J, et al. Retooling food service for early elementary school students in Somerville, Massachusetts: The Shape up Somerville experience. Preventing Chronic Disease. 2009; 6(3):18.

Gosliner 2010 \{published data only\}. Gosliner WA, James P, Yancey AK, Ritchie L, Studer N, Crawford PB. Impact of a worksite wellness program on the nutrition and physical activity environment of child care centers. American Journal of Health Promotion. 2010; 24(3):186-9. [PubMed: 20073385]

Gottesman 2003 \{published data only\} . Gottesman MM. Healthy eating and activity together (HEAT): weapons against obesity. Journal of Pediatric Health Care. 2003; 17(4):210-5. [PubMed: 12847433]

Gottesman 2007 \{published data only\} . Gottesman MM. HEAT: Healthy Eating and Activity Together. AJN. 2007; 107(2):49-50. [PubMed: 17251774]

Graham 2008 \{published data only . Graham D, Appleton S, Rush E, McLennan S, Reed P, Simmons D. Increasing activity and improving nutrition through a schools-based programme: Project Energize. 1. Design, programme, randomisation and evaluation methodology. Public Health Nutrition. 2008; 11(10):1076-84. [PubMed: 18194586]

Gratton 2007 \{published data only\} . Gratton L, Povey R, Clark-Carter D. Promoting children's fruit and vegetable consumption: Interventions using the Theory of Planned Behaviour as a framework. British Journal of Health Psychology. 2007; 12:639-50. [PubMed: 17535489]

Hambleton 2004 \{published data only\} . Hambleton H. Fit 4 Fun. Community Practitioner. 2004; 77(10):367-8.

Havas 1997 \{published data only\}. Havas S, Damron D, Treiman K, Anliker J, Langenberg P, Hammad TA, et al. The Maryland WIC 5 A Day Promotion Program Pilot Study: rationale, results, and lessons learned. Journal of Nutrition Education. 1997; 29(6):343-50.

Heim 2009 \{published data only\} . Heim S, Stang J, Ireland M. A garden pilot project enhances fruit and vegetable consumption among children. Journal of the American Dietetic Association. 2009; 109:1220-6. [PubMed: 19559139]

Hendy 2002 \{published data only\} . Hendy HM. Effectiveness of trained peer models to encourage food acceptance in preschool children. Appetite. 2002; 39:217-25. [PubMed: 12495695]

Hildebrand 2010 \{published data only\} . Hildebrand DA, Shriver LH. A quantitative and qualitative approach to understanding fruit and vegetable availability in low-income AfricanAmerican families with children enrolled in an urban head start program. Journal of the American Dietetic Association. 2010; 110:710-8. [PubMed: 20430132]

Horne 2009 \{published data only\} . Horne PJ, Hardman CA, Lowe CF, Tapper K, Le Noury J, Patel $\mathrm{P}$, et al. Increasing parental provision and children's consumption of lunchbox fruit and vegetables in Ireland: the Food Dudes intervention. European Journal of Clinical Nutrition. 2009; 63:613-8. [PubMed: 18493261]

Horodynski 2004 \{published data only\} . Horodynski MAO, Hoerr S, Coleman G. Nutrition education aimed at toddlers. A pilot program for rural, low-income families. Family and Community Health. 2004; 27(2):103-13. [PubMed: 15596977]

Horodynski 2005 \{published data only\} . Horodynski MA, Stommel M. Nutrition education aimed at toddlers: an intervention study. Pediatric Nursing. 2005; 31(5):364-72. [PubMed: 16295151]

Hu 2010 \{published data only\}. Hu C, Ye D, Li Y, Huang Y, Li L, Gao Y, et al. Evaluation of a kindergarten-based nutrition education intervention for pre-school children in China. Public Health Nutrition. 2010; 13(2):253-60. [PubMed: 19650964]

Hughes 2007 \{published data only\} . Hughes SO, Patrick H, Power TG, Fisher JO, Anderson CB, Nicklas TA. The impact of child care providers' feeding on children's food consumption. Journal of Developmental and Behavioral Pediatrics. 2007; 28(2):100-7. [PubMed: 17435460]

IFIC 2002 \{published data only\} . International Food Information Council. tap into the energy: healthful eating and physical activity tips for kids and parents just a click away. Food Insight. 2002; 1:4-5.Kidnetic.com 
James 1992 \{published data only\}. James J, Brown J, Douglas M, Cox J, Stocker S. Improving the diet of under fives in a deprived inner city practice. Health Trends. 1992; 24:160-4.

Jayne 2009 \{published data only\} . Jayne, CL. Dissertation. The University of Mississippi; 2008. Elmo eats broccoli: a look at the influence of popular characters on children's food choices.

Johnson 1993 \{published data only\} . Johnson Z, Howell F, Molloy B. Community mothers' programme: randomised controlled trial of non-professional intervention in parenting. BMJ. 1993; 306:1449-52. [PubMed: 8518642]

Johnson 2007 \{published data only\} . Johnson SL, Bellows L, Beckstrom L, Anderson J. Evaluation of a social marketing campaign targeting preschool children. American Journal of Health Behavior. 2007; 31(1):44-55. [PubMed: 17181461]

Kalb 2005 \{published data only\} . Kalb C, Springen K. Pump up the family. Newsweek. 2005; 145(17):62. [PubMed: 17848056]

Kashani 1991 \{published data only\} . Kashani IA, Langer RD, Criqui MH, Nader PR, Rupp J, Sallis JF, et al. Effects of parental behavior modification on children's cardiovascular risks. Annals New York Academy of Sciences. 1991; 623:447-9.

Kelder 1995 \{published data only\} . Kelder SH, Perry CL, Lytle LA, Klepp K-I. Community-wide youth nutrition education: long-term outcomes of the Minnesota Heart Health program. Health Education Research. 1995; 10(2):119-31. [PubMed: 10160226]

Khoshnevisan 2004 \{published data only\} . Khoshnevisan F, Kimiagar M, Kalantaree N, Valaee $\mathrm{N}$, Shaheedee N. Effect of nutrition education and diet modification in iron depleted preschool children in nurseries in Tehran: a pilot study. International Journal for Vitamin and Nutrition Research. 2004; 74(4):264-8. [PubMed: 15580808]

Kidala 2000 \{published data only $\quad$. Kidala D, Greiner T, Gebre-Medhin M. Five-year follow-up of a food-based vitamin A intervention in Tanzania. Public Health Nutrition. 2000; 3(4):425-31. [PubMed: 11135797]

Kilaru 2005 \{published data only\} . Kilaru A, Griffiths PL, Ganapathy S, Shanti G. Communitybased nutrition education for improving infant growth in rural Karnataka. Indian Pediatrics. 2005; 42:425-32. [PubMed: 15923688]

Korwanich 2008 \{published data only\} . Korwanich K, Sheiham A, Srisuphan W, Srisilapanan P. Promoting healthy eating in nursery schoolchildren: a quasi-experimental intervention study. Health Education Journal. 2008; 67(1):16-30.

LaRowe 2010 \{published data only\} . LaRowe TL, Adams AK, Jobe Jr, Cronin KA, Vannatter SM, Prince RJ. Dietary intakes and physical activity among preschool-aged children living in rural American Indian communities before a family-based healthy lifestyle intervention. Journal of the American Dietetic Association. 2010; 110:1049-57. [PubMed: 20630162]

Leahy 2008 \{published data only\} . Leahy KE, Birch LL, Fisher JO, Rolls BJ. Reductions in entree energy density increase children's vegetable intake and reduce energy intake. Obesity. 2008; 16(7):1559-65. [PubMed: 18451770]

Locard 1987 \{published data only\} . Locard E, Boyer M, Beroujon M. Evaluation of an educational campaign on nutrition among five years old children. Archives Francaises de Pediatrie. 1987; 44:205-9. [PubMed: 3579487]

Low 2007 \{published data only\} . Low JW, Arimond M, Osman N, Cunguara B, Zano F, Tschirley D. Ensuring the supply of and creating demand for a biofortified crop with a visible trait: Lessons learned from the introduction of orange-fleshed sweet potato in drought-prone areas of Mozambique. Food and Nutrition Bulletin. 2007; 28(2):S258-S270. [PubMed: 17658072]

Luepker 1996 \{published data only\} . Luepker RV, Perry CL, McKinlay SM, Nader PR, Parcel GS, Stone EJ, et al. Outcomes of a field trial to improve children's dietary patterns and physical activity. JAMA. 1996; 275:768-76. [PubMed: 8598593]

Malekafzali 2000 \{published data only\} . Malekafzali H, Abdollahi Z, Mafi A, Naghavi M. Community-based nutritional intervention for reducing malnutrition among children under 5 years of age in the Islamic Republic of Iran. Eastern Mediterranean Health Journal. 2000; 6(2/3): 238-45. [PubMed: 11556008]

Manios 2009 \{published data only\} . Manios Y, Kourlaba G, Kondaki K, Grammatikaki E, Birbilis M, Oikonomou E, et al. Diet quality of preschoolers in Greece based on the healthy eating index: 
The GENESIS study. Journal of the American Dietetic Association. 2009; 109:616-23.

[PubMed: 19328256]

Martens 2008 \{published data only\}. Martens MK, Van Assema P, Paulussen TGWM, Van Breukelen G, Brug J. Krachtvoer-: effect evaluation of a Dutch healthful diet promotion curriculum for lower vocational schools. Public Health Nutrition. 2008; 11(3):271-8. [PubMed: 17605839]

McAuley 2010 \{published data only\} . McAuley KA, Taylor RW, Farmer VL, Hansen P, Williams SM, Booker CS, et al. Economic evaluation of a community-based obesity prevention program in children: the APPLE project. Obesity. 2009; 18:131-6. [PubMed: 19444231]

McKenzie 1996 \{published data only\}. McKenzie J, Dixon LB, Smiciklas-Wright H, Mitchell D, Shannon B, Tershakovec A. Change in nutrient intakes, number of servings, and contributions of total fat from food groups in 4- to 10-year-old children enrolled in a nutrition education study. Journal of the American Dietetic Association. 1996; 96(9):865-72. [PubMed: 8784330]

NAPNAP 2006 \{published data only\} . National Association of Pediatric Nurse Practitioners. Healthy Eating and Activity Together (HEAT) Clinical Practice Guideline: Identifying and preventing overweight in childhood. Journal of Pediatric Health Care. 2006; 20(2):1-64.

Nemet 2007 \{published data only\} . Nemet D, Perez S, Reges O, Eliakim A. Physical activity and nutrition knowledge and preferences in kindergarten children. International Journal of Sports Medicine. 2007; 28:887-90. [PubMed: 17497596]

Nemet 2008 \{published data only\} . Nemet D, Barzilay-Teeni N, Eliakim A. Treatment of childhood obesity in obese families. Journal of Pediatric Endocrinology \& Metabolism. 2008; 21:461-7. [PubMed: 18655528]

Niederer 2009 \{published data only\} . Niederer I, Kriemler S, Zahner L, Burgi F, Ebenegger V, Hartmann T, et al. Influence of a lifestyle intervention in preschool children on physiological and psychological parameters (Ballabeina): study design of a cluster randomized controlled trial. BMC Public Health. 2009; 9:94. [PubMed: 19335890]

Noller 2006 \{published data only\} . Noller B, Winkler G, Rummel C. BeKi - an initiative for nutrition education in children: program description and evaluation. Gesundheitswesen. 2006; 68:165-70. [PubMed: 16575696]

O'Connor 2010 \{published data only . O'Connor TM, Hughes SO, Watson KB, Baranowski T, Nicklas TA, Fisher JO, et al. Parenting practices are associated with fruit and vegetable consumption in preschool children. Public Health Nutrition. 2010; 13(1):91-101. [PubMed: 19490734]

Olvera 2010 \{published data only\} . Olvera N, Bush JA, Sharma SV, Knox BB, Scherer RL, Butte NF. BOUNCE: a community-based mother-daughter healthy lifestyle intervention for lowincome Latino families. Obesity. 2010; 18(1):S102-S104. [PubMed: 20107454]

Panunzio 2007 \{published data only\} . Panunzio MF, Antoniciello A, Pisano A, Dalton S. Nutrition education intervention by teachers may promote fruit and vegetable consumption in Italian students. Nutrition Research. 2007; 27:524-8.

Parcel 1989 \{published data only\}. Parcel GS, Simons-Morton B, O’Hara NM, Baranowski T, Wilson B. School promotion of healthful diet and physical activity: impact on learning outcomes and self reported behavior. Health Education \& Behavior. 1989; 16(1):191-9.

Passehl 2004 \{published data only\} . Passehl B, McCarroll C, Buechner J, Gearring C, Smith AE, Trowbridge F. Preventing childhood obesity: establishing healthy lifestyle habits in the preschool years. Journal of Pediatric Health Care. 2004; 18(6):315-9. [PubMed: 15523425]

Perry 1985 \{published data only . Perry CL, Mullis RM, Maile MC. Modifying the eating behaviour of young children. Journal of School Health. 1985; 55(10):399-402. [PubMed: 3853032]

Perry 1998 \{published data only\}. Perry CL, Lytle LA, Feldman H, Nicklas T, Stone E, Zive M, et al. Effects of the child and adolescent trial for cardiovascular health $(\mathrm{CATCH})$ on fruit and vegetable intake. Journal of Nutrition Education. 1998; 30:354-60.

Rahman 1994 \{published data only\} . Rahman MM, Islam MA, Mahalanabis D, Chowdhury S, Biswas E. Impact of health education on the feeding of green leafy vegetables at home to 
children of the urban poor mothers of Bangladesh. Public Health. 1994; 108:211-8. [PubMed: 8036264]

Ransley 2007 \{published data only\} . Ransley JK, Greenwood DC, Cade JE, Blenkinsop S, Schagen I, Teeman D, et al. Does the school fruit and vegetable scheme improve children's diet? A non-randomised controlled trial. Journal of Epidemiology and Community Health. 2007; 61:699-703. [PubMed: 17630369]

Reinaerts 2007 \{published data only\} . Reinaerts E, de Nooijer J, Candel M, de Vries N. Increasing children's fruit and vegetable consumption: distribution or a multicomponent programme? Public Health Nutrition. 2007; 10(9):939-47. [PubMed: 17381944]

Reinaerts 2008 \{published data only\} . Reinaerts E, Crutzen R, Candel M, De Vries NK, De Nooijer J. Increasing fruit and vegetable intake among children: comparing long-term effects of a free distribution and multicomponent program. Health Education Research. 2008; 23(3):987-96. [PubMed: 18550582]

Reverdy 2008 \{published data only . Reverdy C, Chesnel F, Schlich P, Koster EP, Lange C. Effect of sensory education on willingness to taste novel food in children. Appetite. 2008; 51:156-65. [PubMed: 18342395]

Ruottinen 2008 \{published data only\} . Ruottinen S, Niinikoski H, Lagström H, Rönnemaa T, Hakanen M, Viikari J, et al. High sucrose intake is associated with poor quality of diet and growth between 13 months and 9 years of age: The Special Turku Coronary Risk Factor Intervention Project. Pediatrics. 2008; 121:e1676-e1685. [PubMed: 18519471]

Salminen 2005 \{published data only . Salminen M, Vahlberg T, Ojanlatva A, Kivela SL. Effects of a controlled family-based health education/counseling intervention. American Journal of Health Behavior. 2005; 29(5):395-406. [PubMed: 16201856]

Sanigorski 2008 \{published data only\} . Sanigorski AM, Bell AC, Kremer PJ, Cuttler R, Swinburn BA. Reducing unhealthy weight gain in children through community capacity-building: results of a quasi-experimental intervention program, Be Active Eat Well. International Journal of Obesity. 2008; 32:1060-7. [PubMed: 18542082]

Schwartz 2007a \{published data only\} . Schwartz RP, Hamre R, Dietz WH, Wasserman RC, Slora EJ, Myers EF, et al. Office-based motivational interviewing to prevent childhood obesity. Archives of Pediatrics and Adolescent Medicine. 2007; 161:495-501. [PubMed: 17485627]

Schwartz 2007b \{published data only\}. Schwartz MB. The influence of a verbal prompt on school lunch fruit consumption: a pilot study. International Journal of Behavioral Nutrition and Physical Activity. 2007; 4:6. [PubMed: 17338812]

Siega-Riz 2004 \{published data only\} . Siega-Riz AM, Kranz S, Blanchette D, Haines PS, Guilkey DK, Popkin BM. The effect of participation in the WIC program on preschoolers' diets. The Journal of Pediatrics. 2004; 144:229-34. [PubMed: 14760267]

Simons-Morton 1988 \{published data only\} . Simons-Morton BG, Parcel GS, O’Hara NM. Implementing organizational changes to promote healthful diet and physical activity at school. Health Education \& Behavior. 1988; 15:115-30.

Solomons 1999 \{published data only . Solomons NW. Plant sources of vitamin A and human nutrition: how much is still too little? Nutrition Reviews. 1999; 57(11):350-61. [PubMed: 10628186]

Sweitzer 2010 \{published data only\} . Sweitzer SJ, Briley ME, Roberts-Gray C, Hoelscher DM, Harrist RB, Staskel DM, et al. Lunch is in the bag: increasing fruits, vegetables, and whole grains in sack lunches of preschool-aged children. Journal of the American Dietetic Association. 2010; 110:1058-64. [PubMed: 20630163]

Talvia 2006 \{published data only\} . Talvia S, Räsänen L, Lagström H, Pahkala K, Viikari J, Rönnemaa T, et al. Longitudinal trends in consumption of vegetables and fruit in Finnish children in an atherosclerosis prevention study (STRIP). European Journal of Clinical Nutrition. 2006; 60:172-80. [PubMed: 16234839]

Taylor 2007 \{published data only\} . Taylor RW, McAuley KA, Barbezat W, Strong A, Williams SM, Mann JI. APPLE project: 2-y findings of a community-based obesity prevention program in primary school-age children. American Journal of Clinical Nutrition. 2007; 86:735-42. [PubMed: 17823440] 
Uicab-Pool 2009 \{published data only\} . Uicab-Pool GA, Ferriani MGC, Gomes R, PelcastreVillafuerte B. Representations of eating and of a nutrition program among female caregivers of children under 5 years old in Tizimin, Yucatan, Mexico. Revista Latino-Americana de Enfermagem. 2009; 17(6):940-6. [PubMed: 20126934]

Van Horn 2005 \{published data only\} . Van Horn L, Obarzanek E, Aronson Friedman L, Gernhofer N, Barton B. Children's adaptations to a fat-reduced diet: The Dietary Intervention Study in Children (DISC). Pediatrics. 2005; 115:1723-33. [PubMed: 15930237]

Vecchiarelli 2005 \{published data only\} . Vecchiarelli S, Prelip M, Slusser W, Weightman H, Neumann C. Using participatory action research to develop a school-based environmental intervention to support healthy eating and physical activity. American Journal of Health Education. 2005; 36(1):35-42.

Veldhuis 2009 \{published data only . Veldhuis L, Struijk MK, Kroeze W, Oenema A, Renders CM, Bulk-Bunschoten AMW, et al. 'Be active, eat right', evaluation of an overweight prevention protocol among 5-year-old children: design of a cluster randomised controlled trial. BMC Public Health. 2009; 9:177. [PubMed: 19505297]

Wardle 2003b \{published data only\} . Wardle J, Herrera M-L, Gibson EL. Modifying children's food preferences: the effects of exposure and reward on acceptance of an unfamiliar vegetable. European Journal of Clinical Nutrition. 2003; 57:341-8. [PubMed: 12571670]

Whaley 2010 \{published data only\} . Whaley SE, McGregor S, Jiang L, Gomez J, Harrison G, Jenks E. A WIC-based intervention to prevent early childhood overweight. Journal of Nutrition Education and Behavior. 2010; 42(3S):S47-S51. [PubMed: 20399409]

Winkler 2005 \{published data only\}. Winkler G, Noller B, Waibel S, Wiest M. BeKi - an initiative for nutrition education in children in the federal state of Baden-Wurttemberg: description, experiences, and considerations for an evaluation framework. Praventivmed. 2005; 50:151-60.

Zotor 2008 \{published data only\} . Zotor FB, Amuna P. The food multimix concept: new innovative approach to meeting nutritional challenges in Sub-Saharan Africa. Proceedings of the Nutrition Society. 2008; 67:98-104. [PubMed: 18234137]

\section{References to ongoing studies}

Adams 2009 \{published data only\} . Adams J, Zask A, Dietrich U. Tooty Fruity Vegie in Preschools: an obesity prevention intervention in preschools targeting children's movement skills and eating behaviours. Health Promotion Journal of Australia. 2009; 20:112-19. [PubMed: 19642959]

Campbell 2008 \{published data only\} . Campbell K, Hesketh K, Crawford D, Salmon J, Ball K, McCallum Z. The Infant Feeding Activity and Nutrition Trial (INFANT) an early intervention to prevent childhood obesity: Cluster-randomised controlled trial. BMC Public Health. 2008; 8:103. [PubMed: 18373877]

Daniels 2009 \{published data only\} . Daniels LA, Magarey A, Battistutta D, Nicholson JM, Farrell A, Davidson G, et al. The NOURISH randomised control trial: Positive feeding practices and food preferences in early childhood - a primary prevention program for childhood obesity. BMC Public Health. 2009; 9:387. [PubMed: 19825193]

Wen 2007 \{published data only\} . Wen LM, Baur LA, Rissel C, Wardle K, Alperstein G, Simpson JM. Early intervention of multiple home visits to prevent childhood obesity in a disadvantaged population: a home-based randomised controlled trial (Healthy Beginnings Trial). BMC Public Health. 2007; 7:76. [PubMed: 17490492]

Wyse 2010 \{published data only\} . Wyse RJ, Wolfenden L, Campbell E, Brennan L, Campbell KJ, Fletcher A, et al. A cluster randomised trial of a telephone-based intervention for parents to increase fruit and vegetable consumption in their 3- to 5-year-old children: study protocol. BMC Public Health. 2010; 10:216. [PubMed: 20423524] 


\section{Additional references}

Ajzen 1991 . Ajzen I. The theory of planned behavior. Organizational Behavior and Human Decision Processes. 1991; 50(2):179-211.

Antova 2003 . Antova T, Pattenden S, Nikiforov B, Leonardi GS, Boeva B, Fletcher T, et al. Nutrition and respiratory health in children in six Central and Eastern European countries. Thorax. 2003; 58(3):231-6. [PubMed: 12612301]

Australian Institute of Health and Welfare 2002 . Australian Institute of Health and Welfare. Chronic diseases and associated risk factors in Australia 2001. AIHW; 2002.

Bandura 1986 . Bandura, A. Social foundations of thought and action: A social cognitive theory. Prentice Hall; Englewood Cliffs, New Jersey: 1986.

Blanchette 2005 . Blanchette L, Brug J. Determinants of fruit and vegetable consumption among 6-12 year old children and effective interventions to increase consumption. Journal of Human Nutrition and Dietetics. 2005; 18(6):431-43. [PubMed: 16351702]

Burchett 2003 . Burchett H. Increasing fruit and vegetable consumption among British primary school children: a review. Health Education. 2003; 103(2):99-109.

Campbell 2007 . Campbell KJ, Hesketh KD. Strategies which aim to positively impact on weight, physical activity, diet and sedentary behaviours in children from zero to five years. A systematic review of the literature. Obesity Reviews. 2007; 8:327-38. [PubMed: 17578382]

Ciliska 2000 . Ciliska D, Miles E, O’Brien MA, Turl C, Tomasik HH, Donovan U, et al. Effectiveness of community-based interventions to increase fruit and vegetable consumption. Journal of Nutrition Education. 2000; 32(6):341-52.

Contento 1995 . Contento I, Balch GI, Bronner YL, Lytle LA, Maloney SK, Olson CM, et al. The effectiveness of nutrition education and implications for nutrition education policy, programs, and research: a review of research. Journal of Nutrition Education. 1995; 27(6):277-418.

Delgado-Noguera 2011 . Delgado-Noguera M, Tort S, Martinez-Zapata MJ, Bonfill X. Primary school interventions to promote fruit and vegetable consumption: a systematic review and metaanalysis. Preventive Medicine. 2011; 53:3-9. [PubMed: 21601591]

Elkan 2000 . Elkan R, Kendrick D, Hewitt M, Robinson JJA, Tolley K, Blair M, et al. The effectiveness of domiciliary health visiting: a systematic review of international studies and a selective review of the British literature. Health Technology Assessment. 2000; 4(13):1-339.

Fitzgibbon 2005 . Fitzgibbon ML, Stolley MR, Schiffer L, Van Horn L, KauferChristoffel K, Dyer A. Two-year follow-up results for Hip-Hop to Health Jr.: a randomized controlled trial. The Journal of Pediatrics. 2005; 146(5):618-25. [PubMed: 15870664]

Fitzgibbon 2006 . Fitzgibbon ML, Stolley MR, Schiffer L, Van Horn L, KauferChristoffel K, Dyer A. Hip-Hop to Health Jr. for Latino preschool children. Obesity. 2006; 14:1616-52. [PubMed: 17030973]

Fjeldsoe 2011 . Fjeldsoe B, Neuhaus M, Winkler E, Eakin E. Systematic review of maintenance of behaviour change following physical activity and dietary interventions. Health Psychology. 2011; 30(1):99-109. [PubMed: 21299298]

Forastiere 2005 . Forastiere F, Pistelli R, Sestini P, Fortes C, Renzoni E, Rusconi F, et al. Consumption of fresh fruit rich in vitamin $\mathrm{C}$ and wheezing symptoms in children. Thorax. 2000; 55(4):283-8. [PubMed: 10722767]

French 2003 . French SA, Stables G. Environmental interventions to promote vegetable and fruit consumption among youth in school settings. Preventive Medicine. 2003; 37(6 Pt 1):593-610. [PubMed: 14636793]

Hebert 1995 . Hebert JR, Clemow L, Pbert L, Ockene IS, Ockene JK. Social desirability bias in dietary self-report may compromise the validity of dietary intake measures. International Journal of Epidemiology. 1995; 24:389-98. [PubMed: 7635601]

Hector 2008 . Hector, D.; Shrewsbury, V. Module 2: Interventions to increase consumption of fruit and vegetables. NSW Centre for Overweight and Obesity; Sydney: 2008. Building solutions for preventing childhood obesity.

Hendy 1999 . Hendy HM. Comparison of five teacher actions to encourage children's new food acceptance. Annals of Behavioral Medicine. 1999; 21(1):20-6. [PubMed: 18425650] 
Hesketh 2010 . Hesketh KD, Campbell KJ. Interventions to prevent obesity in 0-5 year olds: an updated systematic review of the literature. Obesity. 2010; 18(Suppl. 1):S27-35. [PubMed: 20107458]

Higgins 2011 . Higgins, JPT.; Green, S., editors. Cochrane Handbook for Systematic Reviews of Interventions Version 5.1.0 [updated March 2011]. Available from www.cochrane-handbook.org

Hopewell 2008 . Hopewell S, Wolfenden L, Clarke M. A survey of adverse event reporting in systematic reviews. Journal of Clinical Epidemiology. 2008; 61:597-602. [PubMed: 18411039]

Howerton 2007 . Howerton MW, Bell S, Dodd KW, Berrigan D, Stolzenberg-Solomon R, Nebeling L. School-based nutrition programs produced a moderate increase in fruit and vegetable consumption: Meta and pooling analyses from 7 studies. Journal of Nutrition Education and Behavior. 2007; 39:186-96. [PubMed: 17606244]

James 1992 . James J, Brown J, Douglas M, Cox J, Stocker S. Improving the diet of under fives in a deprived inner city practice. Health Trends. 1992; 24:160-4.

Jones 2011 . Jones R, Sinn N, Campbell KJ, Hesketh K, Denney-Wilson E, Morgan PJ, et al. The importance of long-term follow-up in child and adolescent obesity prevention interventions. International Journal of Pediatric Obesity. 2011; 6:178-81. [PubMed: 21612335]

Klepp 2005 . Klepp KI, Pérez-Rodrigo C, De Bourdeaudhuij I, Due PP, Elmadfa I, Haraldsdóttir J, et al. Promoting fruit and vegetable consumption among European schoolchildren: rationale, conceptualization and design of the Pro Children Project. Annals of Nutrition and Metabolism. 2005; 49(4):212-20. [PubMed: 16088084]

Knai 2006 . Knai C, Pomerleau J, Lock K, McKee M. Getting children to eat more fruit and vegetables: A systematic review. Preventive Medicine. 2006; 42(2):85-95. [PubMed: 16375956]

Lien 2001 . Lien N, Lytle L, Klepp KI. Stability in consumption of fruit, vegetables and sugary foods in a cohort from age 14 to 21. Preventive Medicine. 2001; 33(3):217-26. [PubMed: 11522162]

Lock 2005 . Lock K, Pomerleau J, Causer L, Altmann DR, McKee M. The global burden of disease attributable to low consumption of fruit and vegetables: implications for the global strategy on diet. Bulletin of the World Health Organization. 2005; 83:100-8. [PubMed: 15744402]

Maynard 2003 . Maynard M, Gunnell D, Emmett PM, Frankel S, Davey Smith G. Fruit, vegetables, and antioxidants in childhood and risk of adult cancer: the Boyd Orr cohort. Journal of Epidemiology and Community Health. 2003; 57(3):218-25. [PubMed: 12594199]

Mikkilä 2004 . Mikkilä V, Räsänen L, Raitakari OT, Pietinen P, Viikari J. Longitudinal changes in diet from childhood into adulthood with respect to risk of cardiovascular diseases: The Cardiovascular Risk in Young Finns Study. European Journal of Clinical Nutrition. 2004; 58:1038-45. [PubMed: 15220946]

Miller 2000 . Miller, M.; Stafford, H. An Intervention Portfolio to Promote Fruit and Vegetable Consumption: The process and portfolio. National Public Health Partnership; Melbourne: 2000.

Ness 2005 . Ness AR, Maynard M, Frankel S, Smith GD, Frobisher C, Leary SD, et al. Diet in childhood and adult cardiovascular and all cause mortality: the Boyd Orr cohort. Heart. 2005; 91(7):894-8. [PubMed: 15958357]

Pearson 2008 . Pearson N, Biddle SJH, Gorely T. Family correlates of fruit and vegetable consumption in children and adolescents: a systematic review. Public Health Nutrition. 2008; 12(2):267-83. [PubMed: 18559129]

Prochaska 1984 . Prochaska, JO.; DiClimente, CC. The transtheoretical approach: crossing traditional boundaries of therapy. Dow Jones Irwin; Homewood, Illinois: 1984.

Rasmussen 2006 . Rasmussen M, Krolner R, Klepp KI, Lytle L, Brug J, Bere E, et al. Determinants of fruit and vegetable consumption among children and adolescents: a review of the literature. Part 1: quantitative studies. International Journal of Behavioral Nutrition and Physical Activity. 2006; 3:22. DOI: 10.1186/1479-5868-3-22. [PubMed: 16904006]

Story 2006 . Story M, Kaphingst KM, French S. The role of child care settings in obesity prevention. The Future of Children. 2006; 16(1):143-68. [PubMed: 16532662]

Tedstone 1998 . Tedstone, A.; Aviles, M.; Shetty, P.; Daniels, L. Effectiveness of interventions to promote healthy eating in preschool children aged 1 to 5 years: a review. Vol. 65. Health Education Authority; London: 1998. 
Trauth 2000 . Trauth JM, Musa D, Simminoff L, Jewell IK, Ricci E. Public attitudes regarding willingness to participate in medical research studies. Journal of Health \& Social Policy. 2000; 12(2):23-43. [PubMed: 11184441]

van der Horst 2007 . van der Horst K, Oenema A, Ferreira I, Wendel-Vos W, Giskes K, van Lenthe $\mathrm{F}$, et al. A systematic review of environmental correlates of obesity related dietary behaviors in youth. Health Education Research. 2007; 22(2):203-26. [PubMed: 16861362]

Waters 2011 . Waters E, de Silva-Sanigorski A, Hall BJ, Brown T, Campbell KJ, Gao Y, Armstrong R, Prosser L, Summerbell CD. Interventions for preventing obesity in children. Cochrane Database of Systematic Reviews. 2011; (12) DOI: 10.1002/14651858.CD001871.pub2.

Williams 2004 . Williams CL, Strobino BA, Bollella M, Brotanek J. Cardiovascular risk reduction in preschool children: the "Healthy Start" project. Journal of the American College of Nutrition. 2004; 23:117-23. [PubMed: 15047677]

Wolfenden 2010 . Wolfenden L, Wiggers J, Tursan d'Espaignet E, Bell AC. How useful are systematic reviews of child obesity interventions. Obesity Reviews. 2010; 11:159-65. [PubMed: 19573051]

World Health Organization 1997 . World Health Organization. Diet, nutrition and the prevention of chronic diseases. World Health Organization; Geneva: 1997. Technical Report Series, No. 797

World Health Organization 2003 . World Health Organization. Diet, nutrition and the prevention of chronic diseases. Report of a joint FAO/WHO Expert Consultation. World Health Organization; Geneva: 2003. Technical Report Series, No. 916

World Health Organization 2004a . Currie, C.; Roberts, C.; Morgan, A.; Smith, R.; Settertobulte, W.; Samdal, O., et al. Young peoples health in context. Health Behaviour in School-aged Children (HBSC) study: international report from the 2001/2002 survey. World Health Organization; Denmark: 2004.

World Health Organization 2004b . World Health Organization. Fruit and vegetables for health: Report of a Joint FAO / WHO Workshop. Kobe Japan: Sep 1-3. 2004 Available at: http:// www.who.int/dietphysicalactivity/publications/fruit.vegetables.report.pdf

World Health Organization 2009 . World Health Organization. Global health risks: mortality and burden of disease attributable to selected major risks. WHO; Geneva: 2009.

World Health Organization 2011 . World Health Organization. Global status report on non communicable diseases 2010. WHO; Geneva: 2011.

Worobey 2004 . Worobey J, Pisuk J, Decker K. Diet and behavior in at-risk children: evaluation of an early intervention program. Public Health Nursing. 2004; 21:122-7. [PubMed: 14987211]

Yngve 2005 . Yngve A, Wolf A, Poortvliet E, Elmadfa I, Brug J, Ehrenblad B, et al. Fruit and vegetable intake in a sample of 11 year old children in 9 European countries: the Pro Children cross-sectional Survey. Annals of Nutrition and Metabolism. 2005; 49(4):236-45. [PubMed: 16088087]

* Indicates the major publication for the study 


\section{PLAIN LANGUAGE SUMMARY}

\section{Interventions for increasing fruit and vegetable consumption in children aged 5 years and under}

Insufficient fruit and vegetable consumption represents a considerable health burden in developed countries. Consumption of fruit and vegetables is associated with reductions in the risk of future chronic disease. Early childhood represents a critical period for the establishment of child dietary habits. Interventions to increase consumption of fruit and vegetables in early childhood may, therefore, represent an effective strategy in reducing the disease burden associated with insufficient fruit and vegetable intake. The aim of this review was to assess the impact of interventions designed to increase the consumption of fruit and/or vegetables among children aged five years and under. To identify relevant studies, we searched a variety of electronic bibliographic databases and relevant journals, and considered studies cited by trials included in the review. We also contacted the authors of included trials and asked if they knew of other trials which may be relevant. Any randomised trial of an intervention which primarily sought to increase the fruit and/or vegetable intake of children five years of age and under, and included a dietary or biochemical assessment of consumption, was eligible. Two reviewers independently searched for and extracted relevant information from trials included in the review. Overall, 10,740 citations were examined yielding five trials with 3967 participants which met the review eligibility criteria and were included in the review. Of the five trials, two examined child feeding interventions, two examined home visiting interventions and one examined the impact of a preschool-based intervention. The findings of the included studies suggest that repeatedly exposing children to a target vegetable does not significantly increase short-term ( $<$ three months) child consumption of the target vegetable. One trial which examined coupling repeated food exposure with a tangible non-food, or social reward, found that such strategies were effective in increasing shortterm ( $<$ three months) targeted vegetable consumption. Home visiting interventions were found to be ineffective in increasing child consumption of fruit and/or vegetables overall. Although the preschool-based intervention failed to significantly increase vegetable consumption, a small significant increase in mean child consumption of fruit was reported. The review highlights the paucity of randomised trials of fruit and vegetable interventions for children of this age, and the lack of effective interventions evaluated using such designs available to health policy makers and practitioners. 


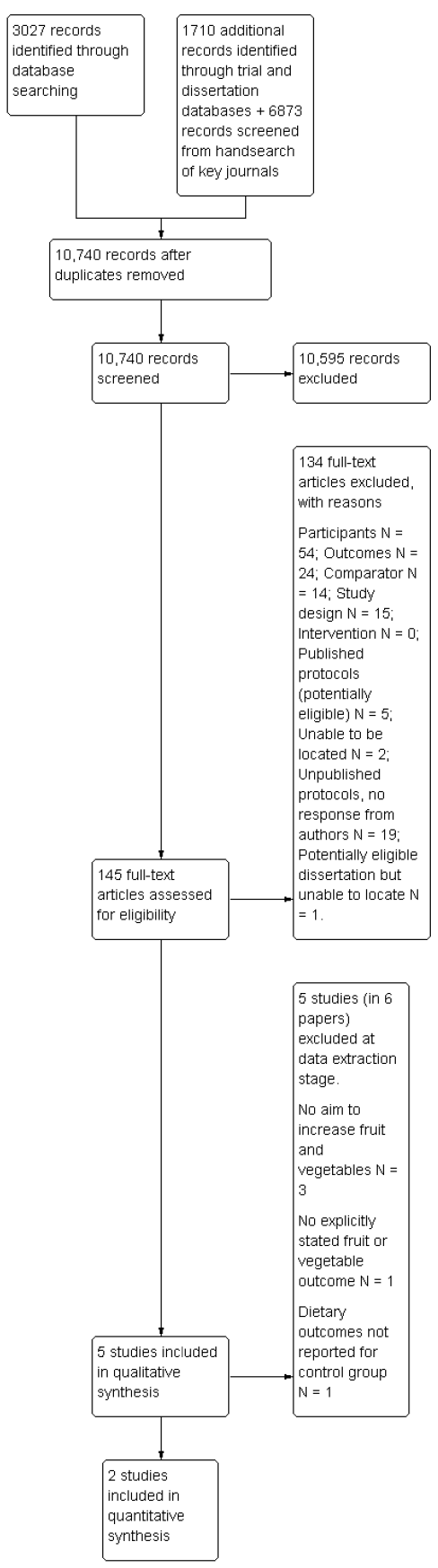

Figure 1. Study flow diagram 


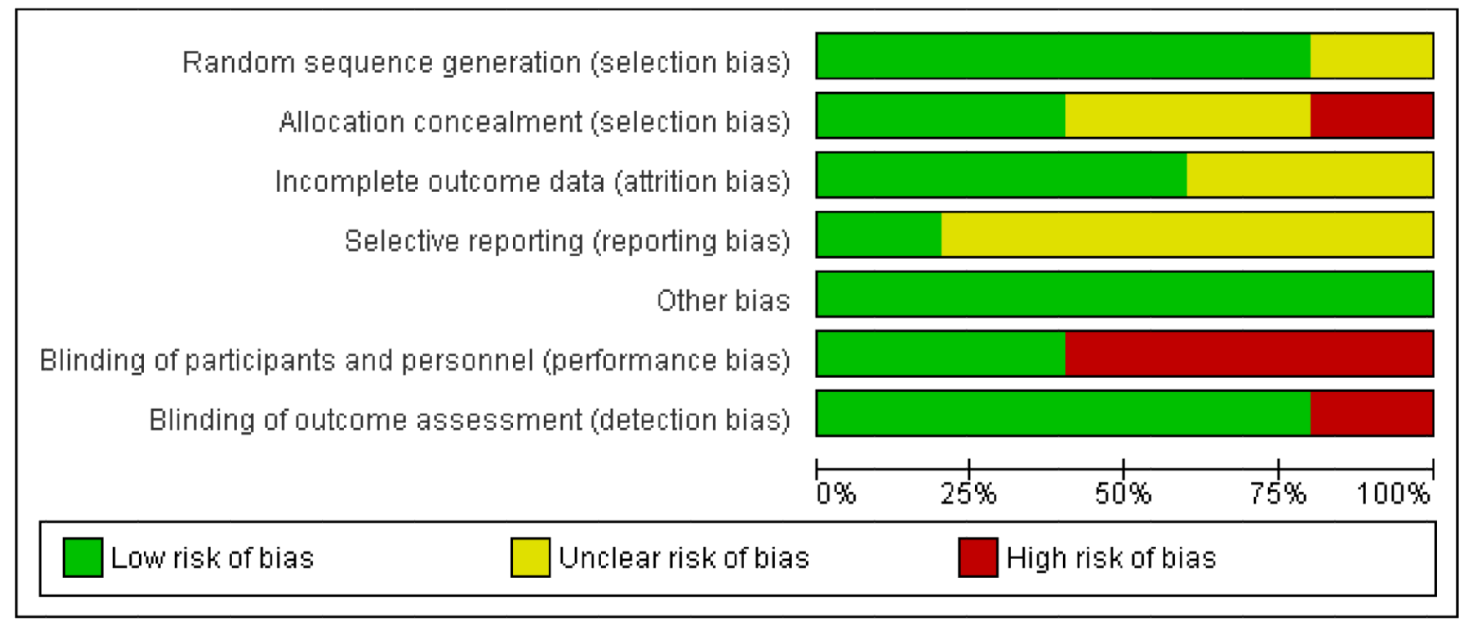

Figure 2. Risk of bias graph: review authors' judgements about each risk of bias item presented as percentages across all included studies 